\title{
Applying urban climate model in prediction mode-evaluation of MUKLIMO_3 model performance for Austrian cities based on the summer period of 2019
}

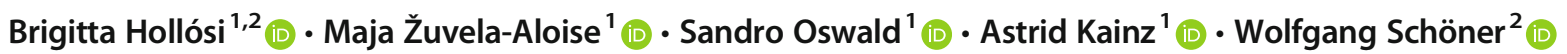

Received: 10 July 2020 / Accepted: 26 February 2021 / Published online: 25 March 2021

(C) The Author(s) 2021

\begin{abstract}
Extreme heat events are natural hazards affecting many regions of the world. This study uses an example of the six largest cities in Austria to demonstrate the potential of urban climate model simulations applied in prediction mode providing detailed information on thermal conditions. For this purpose, the urban climate model MUKLIMO_3 of the German Meteorological Service (DWD) coupled with the hydrostatic numerical weather prediction model, ALARO, is used to simulate the development of the urban heat island (UHI) in Austrian cities for the summer period of 2019 with a horizontal resolution of $100 \mathrm{~m}$. In addition to the evaluation of UHI predicting skills, other relevant variables, such as humidity and wind characteristics on hourly basis, are also analysed in this paper. Model evaluation confirmed that the MUKLIMO_3 microscale model had the capacity to simulate the main thermal spatiotemporal patterns in urban areas; however, a strong dependence on the input data from the mesoscale model was found. Our results showed large benefit in prediction of maximum air temperatures in urban areas, while the relative humidity predictions of MUKLIMO_3 appear to be much less plausible and show large variety of model prediction skills. Urban climate model simulations using real atmospheric conditions can facilitate better quantification and understanding of dayto-day intra-urban variations in microclimate as well as provide a basis for evaluation of the microclimate prediction skills of mesoscale numerical models with urban extensions.
\end{abstract}

\section{Introduction}

In recent years, much attention has been focused on urbaninduced and urban-modified weather and climate. Several studies described differences in atmospherical parameters such as air temperature, humidity, precipitation, wind speed, and energy fluxes between urban and rural areas on short and long timescales (Bornstein and Johnson 1976; Landsberg 1981; Oke 1982; Lee 1991; Cotton and Pielke 1995; Figuerola and Mazzeo 1998; Shepherd et al. 2002; Dixon and Mote 2003; Zuvela-Aloise et al. 2014). One of the most known and well-documented phenomenon is the positive difference of air temperature between urban and rural areas,

Brigitta Hollósi

brigitta.hollosi@zamg.ac.at

1 Zentralanstalt für Meteorologie und Geodynamik, Hohe Warte 38, A-1190 Vienna, Austria

2 Institute of Geography and Regional Science, University of Graz, Heinrichstraße 36, A-8010, Graz, Austria called urban heat island, UHI (Oke 1973). Anthropogenic activities as well as changes in land surface by industrial and socioeconomic development affect heat storage and fluxes and are the main causes of this effect (Oke 1995; Kleerekoper et al. 2012). Extreme temperatures, especially long-lasting heat waves, amplify the urban-rural thermal gradient. Climate change projections show a continuation of the observed warming trend in the next decades with an expected increase in frequency, intensity, and duration of extreme heat events (IPCC 2013). Considering current and expected urbanization trends, the excess in heat combined with reduced nocturnal cooling, decreased ventilation, and related air pollution increases health risks for urban dwellers and makes cities highly vulnerable to climate change impacts (Fischer and Schär 2010; IPCC 2013). Furthermore, heat has become recognized as a significant threat to the environment and the society (Schär and Jendritzky 2004; Kovats and Jendritzky 2006; Robine et al. 2008; Barriopedro et al. 2011). Most of the largest cities experience profound changes due to urbanization, and hence, city administrations are facing challenges in order to safeguard high-quality urban growth despite increasingly tight spatial resources. Recent urban climate research 
focuses on analysis of current and projected heat load conditions of various Central European cities (e.g. Früh et al. 2011; De Ridder et al. 2015; Bokwa et al. 2018), as well as the heat load reduction potential of possible adaptation measures to help combat negative effects of air temperature increase in urban areas (e.g. Hamdi and Schayes 2008; Santamouris et al. 2012; Theeuwes et al. 2013; Fallmann et al. 2014; Zuvela-Aloise et al. 2016).

In order to increase the resilience of cities to current and future extreme heat events and to reduce the negative impacts on public health and urban systems, comprehensive urban planning and risk management strategies have to be developed. Following this approach, WHO and WMO have strengthened their cooperation and co-published the guideline "Heatwaves and Health: Guidance on Warning-System Development" that outlines the main aspects of heat warning system developments and presents a comprehensive analysis on definitions and methodologies and communication of warnings and planning strategies for managing heat events (WMO and WHO 2015). Already beforehand, after the 2003 heat wave, most European countries began to develop and implement early warning systems (Lowe et al. 2011; Casanueva et al. 2019).

There are several methods for determining extreme hightemperature events. The mostly applied approaches refer to a time period during which the air temperature exceeds a certain threshold determined based on epidemiological studies or climatological extremes (e.g. high percentiles) for a certain region, while some countries also consider different meteorological factors (e.g. wind, humidity). Although most of the thresholds include daytime temperatures, nocturnal conditions play an essential role due to the cumulative heat load in densely built areas, leading to increased stress for the human body (Rooney et al. 1998). High temperatures especially in connection with high humidity are associated with significant health risks for the vulnerable groups (e.g. older people, children, patients with cardiovascular and mental illnesses or people living isolated). In 2019, the Austrian Agency for Health and Food Safety (AGES 2020) calculated and published heat associated mortality statistics for Austria based on air temperature data of measurement stations from the Austrian weather service (ZAMG) and the all-cause mortality data from Statistics Austria. Based on the calculations of AGES, extensive heat load claimed in total 198 deaths in Austria over the summer period in 2019.

The capital city Vienna is located in the north-eastern part of Austria and has a population of about 1.89 million, about $21 \%$ of the total population of the country, and is the country's largest city. Graz is second in size, followed by Linz, Salzburg, Innsbruck, and Klagenfurt, the latest having a population of 100.000 inhabitants. According to the demography forecast of Statistics Austria, the population is set to grow in cities, e.g. in Vienna from 1.89 million up to 2.01 million by
2030 and to 2.15 million by 2050 (Statistics Austria 2019). Over the same period, the country's age structure is expected to shift towards older people. Currently about $19 \%$ of the Austrian population is aged 65 or above; this ratio will have risen to $28 \%$ by the mid-century (Statistics Austria 2019) leading to an increase of potential affected people within vulnerable groups by consequences of extreme heat events. A monitoring system for capturing temporal and spatial variability of heat load is of particular importance for risk assessment, as well for further model development purposes. National weather services, as well as city administrations often operate observational stations and provide single-point information on current thermal conditions, but the establishment of an appropriate operational monitoring network in urban areas with high-density and high-quality equipment is very cost-intensive.

In order to predict upcoming heat events and to provide targeted information for decision-making, sub-kilometre scale predictions are necessary. In state-of-the-art operational heat warning systems, the meteorological information relies on the weather forecast from the mesoscale numerical models that do not include details of urban morphology. As the number of people, living in cities, has a continuous increasing trend, special focus should be given on development and preparation activities in these areas. In the last years, lot of efforts have been made to implement appropriate parameterization schemes of urban representation in numerical mesoscale models (e.g. the town energy balance model from Masson (2000) widely used in numerical weather prediction models) and to analyse their feasibility in terms of their capabilities to describe dynamical processes in urban areas (e.g. Grimmond et al. 2010, 2011). Intensive efforts have been made in the community mesoscale weather research fnd Forecasting (WRF) model (Skamarock and Klemp 2008) to improve the assessment of urban influences and effects (Chen et al. 2011) and to introduce it successfully in operational real-time forecasts. Several parameterization approaches (Kusaka et al. 2001; Martilli et al. 2002; Salamanca et al. 2010) were developed to better represent cities and evaluated in a number of different case study regions (e.g. Salamanca et al. 2011; Zhang et al. 2011; Garcia-Diez et al. 2016; Ronda et al. 2017; Göndöcs et al. 2017; Vuckovic et al. 2020, Molnár et al. 2019). However, mesoscale model simulations on a sub-kilometre spatial scale are computationally expensive and therefore hard to apply for weather forecasting purpose in operational mode.

This study is aimed to apply the urban climate model - also referred here as UCM MUKLIMO_3 (Sievers and Zdunkowski 1986; Sievers 1990, 1995) in prediction mode by coupling it uni-directionally with the operational numerical weather prediction (NWP) model ALARO. The model simulations with $100 \mathrm{~m}$ resolution were performed for the summer period from 1 April to 31 October 2019 and were verified using the measurements of the observational stations of the 
cities. This season was selected for the analysis as air temperatures in 2019 were far above the long-term climate average, and the summer was characterized by prolonged heat periods. In order to evaluate the model performance of MUKLIMO_3 in predicting day-to-day heat load characteristics, simulations for the six largest cities of Austria (Vienna, Graz, Linz, Salzburg, Innsbruck, and Klagenfurt), having different topographic features, were analysed. The study evaluates whether the applied methodology and information obtained using the UCM model in combination with the NWP system provides an added value for weather and UHI forecast in urban areas. The analysis includes the evaluation of different meteorological parameters, the computational performance, as well as the UCM dependencies, and limitations will be also discussed.

\section{Data and methodology}

\subsection{Geographic and urban characteristics}

The selected model domains of each city contain the centre, the surrounding suburban, and rural areas as well. A detailed description of main urban characteristics of the analysed cities and information on the fraction of different land cover (LC) and land use (LU) characteristics is given in Table 1.

The orographic information (Fig. 1a, b) for MUKLIMO_3 (model description in Section 2.2) was provided by the European Digital Elevation Model (EU-DEM, version 1.1 from 2016) from the Copernicus Land Monitoring Service. The $25-\mathrm{m}$ spatial resolution dataset was recalculated to the 100-m model grid. Compared to the other analysed cities, the lowest elevation difference (about $400 \mathrm{~m}$ ) is found in Vienna. Linz and Salzburg are placed in the northern part of the Alps, while Graz and Klagenfurt are in the southern region of Austria being affected by different meteorological and climatological conditions due to Alpine region. Innsbruck has a much more complex terrain as it is located in a broad valley between high mountains up to $2700 \mathrm{~m}$.

In previous years, much effort has been spent on the development of accurate LU data sets on local, as well as on international level. Such examples are the Urban Atlas and Corine Land Cover (CLC) data of the Copernicus Land Monitoring Service, the Local Climate Zones (LCZ) classification scheme from Stewart and Oke (2012) supported by World Urban Database (WUDAPT), as well as local data provided by city administrations or national agencies (e.g. LISA dataset for Austria). Due to satellite-based LU recording methods, standardized and multilevel classifications allow the transferability from one city to another and enable comprehensive spatial and temporal comparison of LU inventories. In this study, the Urban Atlas dataset provided by the European Environment Agency within the Copernicus Programme was used (EEA 2010). Urban Atlas offers, in comparison to other available land use datasets, a high level of detail and spatial coverage for large- and middle-size Austrian cities. With a total number of 27 land use classes, it allows a harmonized and continuous monitoring of urban structures for future evaluations. Urban Atlas can easily be used in combination with other relevant available high- and medium-resolution information (e.g. the very high resolution imperviousness layer, the building high layer, street tree layer) from the Copernicus Programme. Figure 1c shows the spatial pattern of LU in the study areas. For modelling purposes, each LU category is characterized by different parameters describing building properties and urban structures, such as fraction of built area (Fig. 1d), mean building height (Fig. 1e), fraction of pavement of the non-built area, information on low vegetation of the remaining surface, as well as tree density, mean vegetation height, and leaf area index considered for the tree trunk and the tree crown area separately (see Table 3 in the Appendix). In order to calculate the required parameters for the model configuration, highquality building dataset and the cadastre of public trees have

Table 1 Urban characteristics of the selected cities: population, size of urban area (Österreichischer Städtebund 2017), and percentage of different land cover and land use areas (built-up, yellow; traffic surface, grey; industry, brown; green areas, green; water surfaces, blue) of the selected

model domain (municipal boundary of the cities and surrounding suburban and rural areas) based on cumulated land use classes of the Urban Atlas classification scheme (EEA 2010)

\begin{tabular}{|c|c|c|c|c|}
\hline City & Population & $\begin{array}{c}\text { Urban } \\
\text { area } \\
{\left[\mathrm{km}^{2}\right]}\end{array}$ & Urban characteristics & $\begin{array}{c}\text { Percentage } \\
\text { of different LC and LU } \\
\text { areas in model domain }\end{array}$ \\
\hline Vienna & 1.867 .582 & 415 & $\begin{array}{l}\text { The urbanized area is characterized by the historical center surrounded by a green belt. Dense built-up areas are placed in } \\
\text { the inner districts and low-density residential areas on the hillsides in the western part as well as in the flat terrain in the } \\
\text { south and east direction. Most of the industrial areas are located in the eastern and southern part of the city. }\end{array}$ & | \\
\hline Graz & 283.869 & 128 & $\begin{array}{l}\text { Graz lies in a basin surrounded by mountains on three sides, causing the city can expand mainly towards the south. Graz is a } \\
\text { green and heavily forested area. }\end{array}$ & \\
\hline Linz & 203.012 & 96 & $\begin{array}{l}\text { The city of Linz is characterized by heavy industry. Former industrial areas have been or are developed into residential areas } \\
\text { and public parks in order to increase the enviromental quality. }\end{array}$ & 口um \\
\hline Salzburg & 152.367 & 66 & $\begin{array}{l}\text { Salzburg is located at the northem boundary of the Alps. Two smaller hills as green reliefs within the city offer opportunity } \\
\text { for leisure activities. }\end{array}$ & \\
\hline Innsbruck & 132.236 & 105 & $\begin{array}{l}\text { The settlement area of Innsbruck is very limited due the complex alpine topography. The valley along the Inn River is } \\
\text { therefore densely populated. The city is spreading mainly towards east and west towards the airport. }\end{array}$ & \\
\hline Klagenfurt & 99.790 & 120 & $\begin{array}{l}\text { Klagenfurt is located close to the lake Worrhersee and it is surrounded by forest-covered hills and mountains. A circuit of } \\
\text { streets, which circles the historical city center boasts many parks and gardens. }\end{array}$ & \\
\hline
\end{tabular}


b)

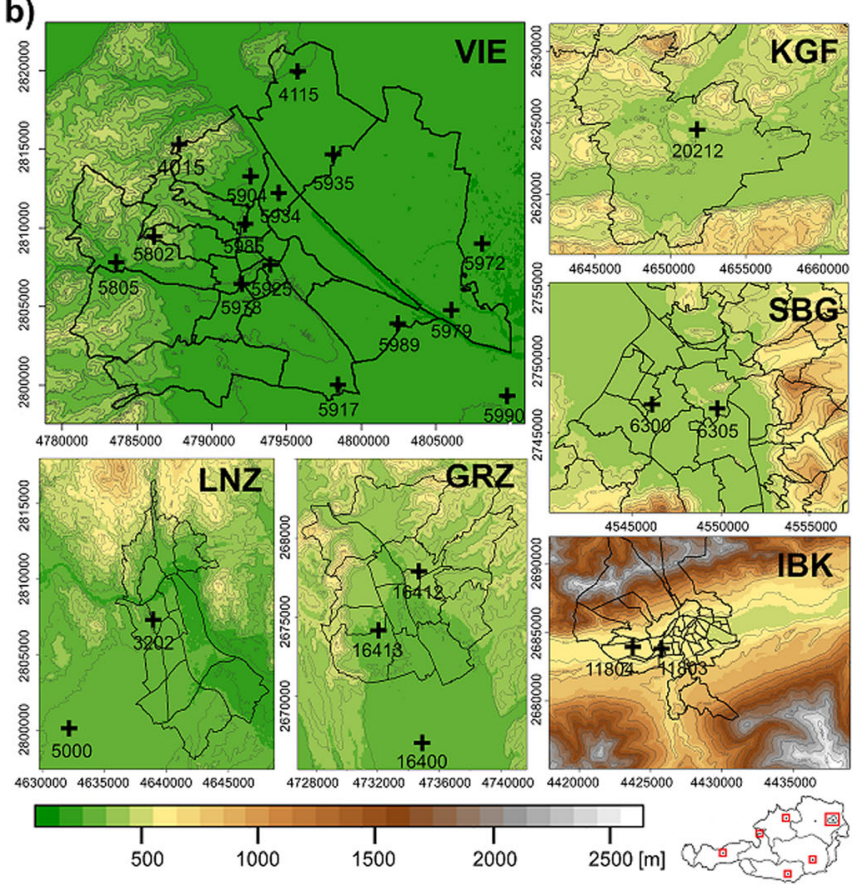

d)

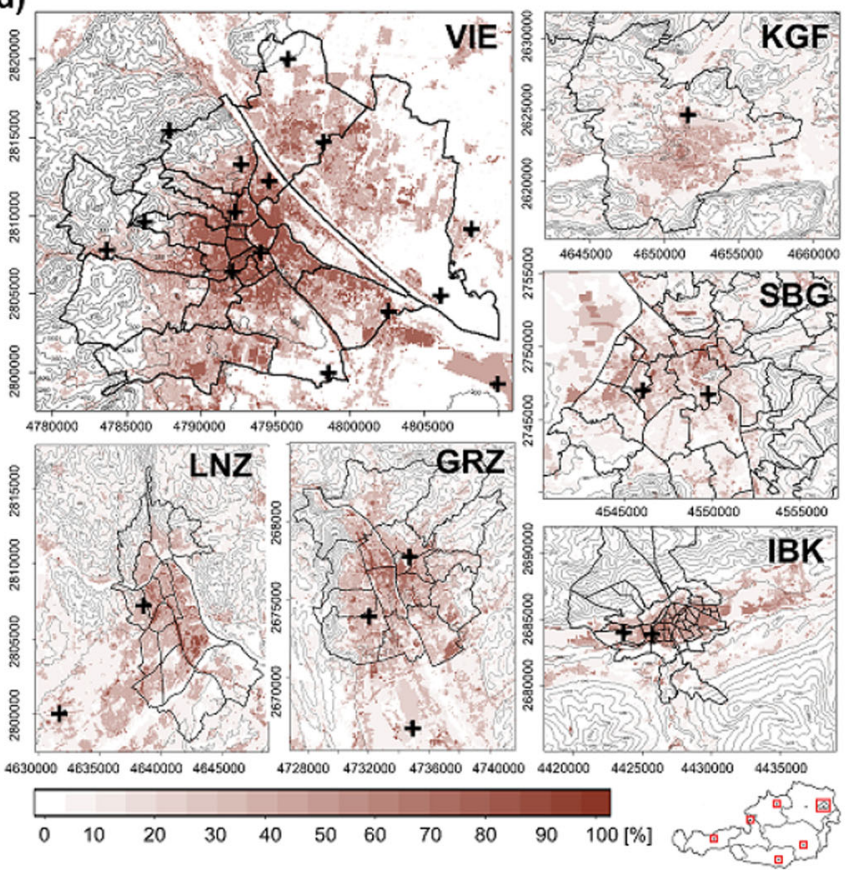

a)
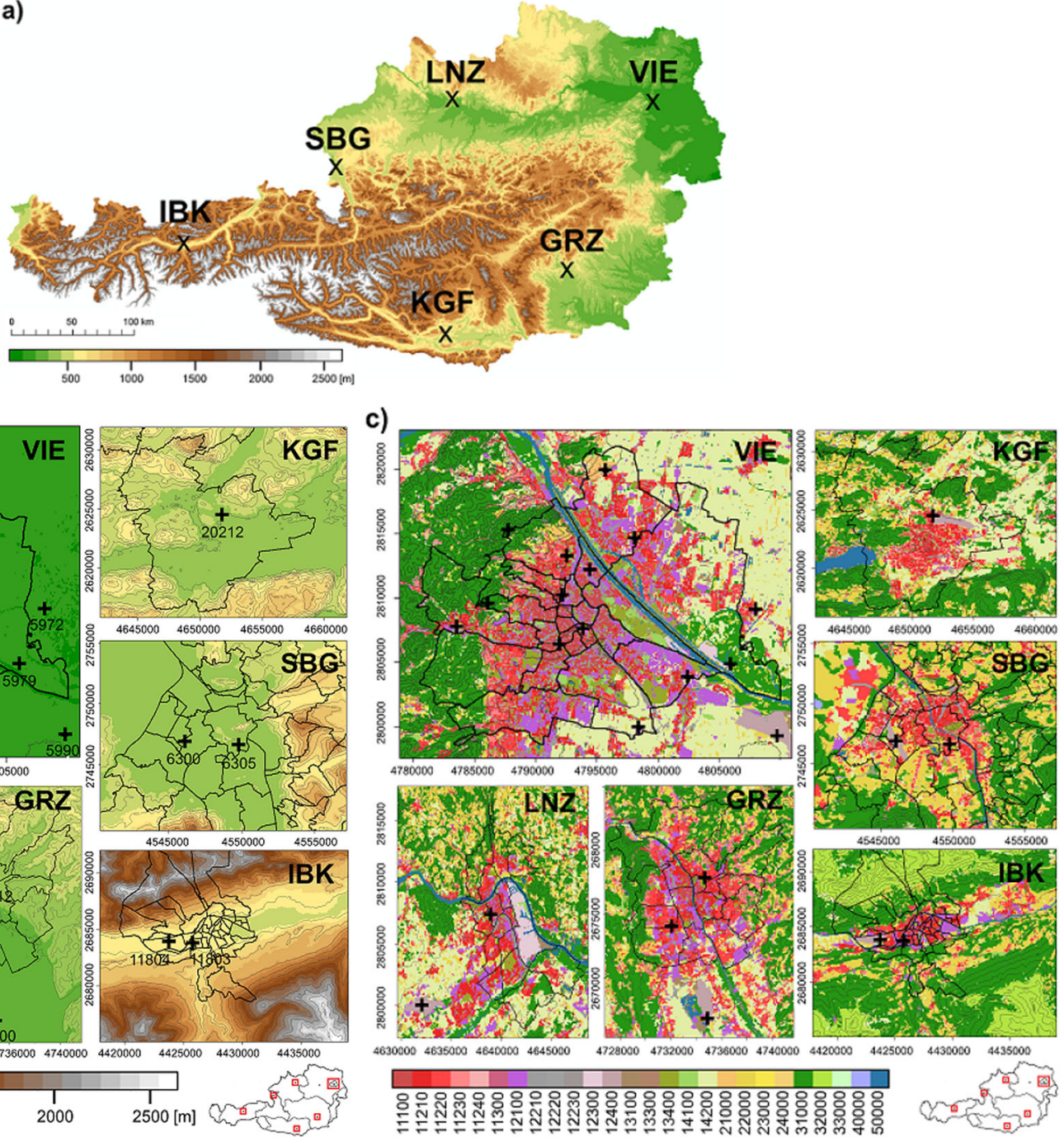

e)

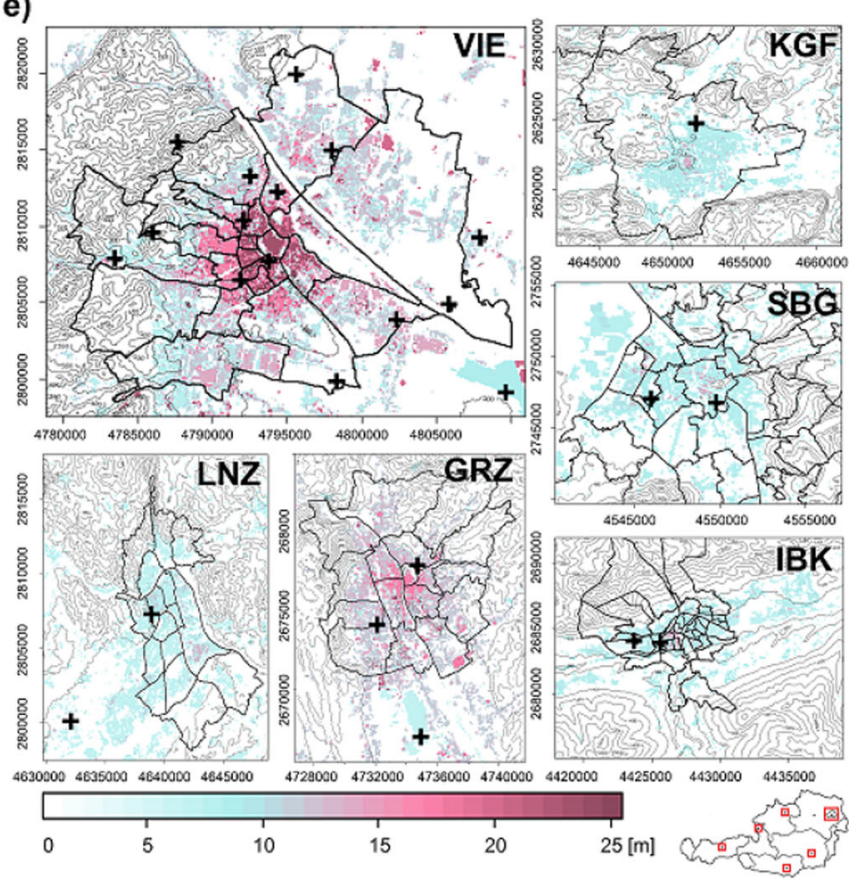


Fig. 1 Orography information based on the European Digital Elevation Model (EU-DEM, version 1.1) from the Copernicus Land Monitoring Service for a Austria and b the analysed cities: Vienna (VIE), Graz (GRZ), Linz (LNZ), Salzburg (SBG), Innsbruck (IBK), and Klagenfurt (KGF), $\mathbf{c}$ land use distribution provided by the Urban Atlas classification (EEA 2010) on a horizontal resolution of $100 \mathrm{~m}$ (see Table 2) for explanation of the land use classes, $\mathbf{d}$ fraction of impervious surfaces, and $\mathbf{e}$ building heights. Black crosses indicate the location of the observational stations of ZAMG and solid black lines the city administration (in case of VIE). Solid grey lines mark orography. Projection: ETRS 89 (EPSG:3035)

been made available by the city administrations of Vienna, Linz (Kainz et al. 2019), Klagenfurt (Oswald et al. 2020), and Salzburg, while parameters for Graz and Innsbruck have been derived from the products of Copernicus Land Monitoring Services (https://land.copernicus.eu) related to imperviousness and tree cover density.

\subsection{Applied mesoscale and urban climate model}

To represent mesoscale weather conditions in the selected urban areas, the dynamical urban climate model MUKLIMO_3 was initialized with the hydrostatic weather forecast model ALARO. The limited-area model ALARO uses the dynamical core had been developed for ALADIN (Bénard et al. 2010; Wang et al. 2006) with a physics package specifically designed to be run at convection-permitting scales (Kann et al. 2015). ALARO has a horizontal resolution of $4.8 \mathrm{~km}, 60$ vertical levels, and provides outputs in hourly intervals. The model is operated four times (00/06/12/18 UTC) per day performing integrations of up to 72-h leading time. The initial state for the free atmosphere and the lateral boundary conditions are provided by the global Integrated Forecast System (IFS) run at the European Centre for Medium-Range Weather Forecasts (ECMWF).

In this study, the non-hydrostatic microscale model MUKLIMO_3 (in German: Mikroskaliges Urbanes Klima Modell) developed by the German Meteorological Service was used to simulate the daily cycle of temperature, relative humidity, and wind characteristics on a high resolution, while considering information on urban structure (Sievers and Zdunkowski 1986; Sievers 1990, 1995, 2016). The analysis in this study relies on the latest thermodynamical version of the model (v190403 from 2019) that is an extension of the basic wind flow and dispersion model from Sievers (1995). The thermodynamical version of the MUKLIMO 3 atmospheric flow model has been developed for microscale urban climate and planning applications (Sievers and Zdunkowski 1986; Sievers 1990) by using a dynamical-statistical downscaling technique called cuboid method (Früh et al. 2011) and was applied mainly for climatological studies so far. Bokwa et al. (2019) evaluated for the first time the performance of
MUKLIMO 3 predicting skills for a heat wave period from 2015 for different Central European cities. MUKLIMO_3 provides a tool for various scientific applications on the urban scale (e.g. urban flow, cold air drainage, urban heat island) and was designed to simulate the diurnal cycles of atmospheric variables on a three-dimensional model grid (Sievers 2016). The model physics include prognostic equations for atmospheric temperature and humidity, the parameterisation of unresolved buildings, short-wave and long-wave radiation, balanced heat and moisture budgets in the soil (Sievers et al. 1983), and a vegetation model based on Siebert et al. (1992), but neither the physical depiction of cloud formation and precipitation processes nor the influence of anthropogenic heat is integrated in it. The flow between buildings is parametrized through a porous media approach for unresolved buildings (Gross 1989) that are characterized with the volume fraction (area and height) and the wall area of the buildings within the grid cell. To perform model simulations and to describe the geographical and urban characteristics of study areas, input datasets such as terrain height, LU information, and the structural description (outlined in Section 2.1) of the city area are required. Additionally, meteorological information is needed to initialize the model under real atmospherical conditions, which was derived from the NWP model ALARO in this study.

\subsection{Modelling approach}

High-resolution simulations were performed for six Austrian cities for a 7-month long period over the extreme hot summer of 2019 (from 1 April to 31 October 2019). For the model chain (Fig. 2), information on total cloud cover, wind characteristics, and vertical profiles of temperature and humidity of the ALARO $0600+0000$ UTC analysis fields were extracted for 9 ALARO pressure levels up to about a 2-km height and averaged for a $4 \times 4$ grid $(2 \times 2$ grid in case of parameter wind speed) area close to the city. Reference areas were selected within the ALARO domain outside of the city in rural environment in order to ensure the meteorological input data is not being influenced by urban effects directly. Surface temperature of open water was considered as monthly climatological averages based on Pekarova et al. (2008). To calculate the heat flow through building walls and roofs, the indoor temperature values were estimated based on the relationship between indoor and outdoor temperature described by Nguyen et al. (2013). As soil temperature and moisture values were not available in NWP model outputs during the analysis, these parameters were provided by the monitoring stations of the cities based on the daily mean value for soil temperature and the 06 UTC observation of soil moisture.

After the NWP model provides the initialization fields, the $1 \mathrm{D}$ version of the MUKLIMO 3 model was started at 06 UTC. The $1 \mathrm{D}$ model calculates the daily cycle of temperature, 


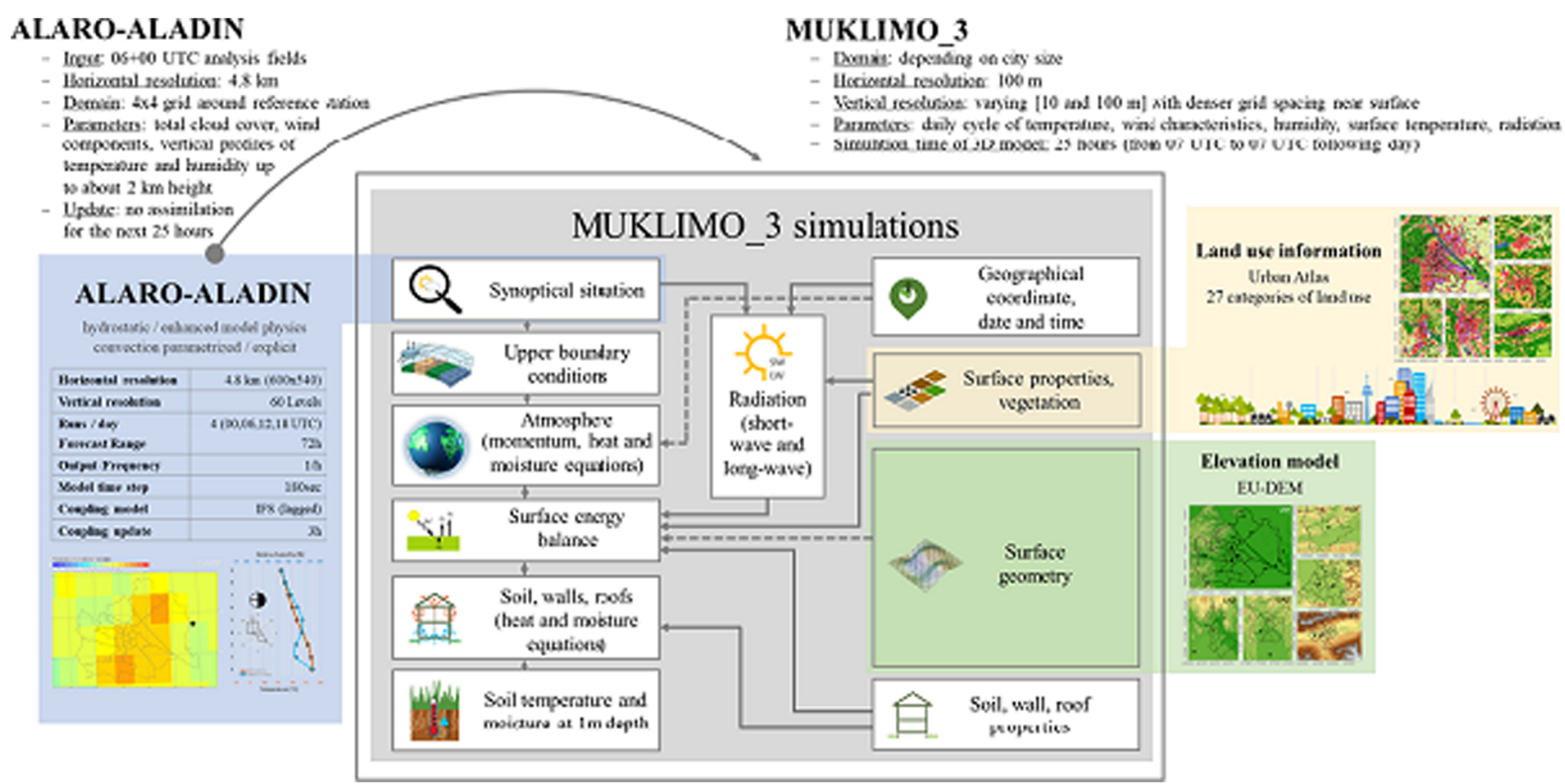

Fig. 2 Schematic structure of the MUKLIMO 3 modelling approach in prediction mode, illustrating the main model components (center), required input data (left), and information in terms of data preparation (right) after Bokwa et al. (2019)

relative humidity, and wind for the reference station located outside of the urban area, considering the geographic position, height, soil type, and LU characteristics of the reference station. The $3 \mathrm{D}$ simulation is then initialised and driven by the $1 \mathrm{D}$ version of the MUKLIMO_3 model and provides the upper boundary conditions for the entire duration of the $3 \mathrm{D}$ model run from 07 UTC by providing hourly values for wind, air temperature, and relative humidity at the top layer of the 3D model. The lateral sides of the 3D model have free boundary conditions with horizontal advection terms being zero at the upstream domain boundaries (Zuvela-Aloise 2017). In order to reproduce an entire daily cycle of $24 \mathrm{~h}$, a simulation time of $25 \mathrm{~h}$ was defined in the model. However, the first hour of the 3D model simulation, where the applied initial vertical profiles from the 1D model are adjusted for the urban area, is excluded from the analysis (remaining data from 08 UTC up to 07 UTC on the following day). Only the meteorological fields given as the output of the 3D model are used for the analysis of the UHI effect. During the simulation period of $25 \mathrm{~h}$, MUKLIMO_3 initialised with $0600+0000$ UTC NWP analysis fields of ALARO was not updated and assimilated with NWP outputs anymore.

The indicated parameters were embedded in the UCM to provide initial and boundary conditions for MUKLIMO_3 and to simulate urban heat load characteristics under real conditions on $100 \mathrm{~m}$ horizontal resolution. Depending on the size of the city including suburban and rural areas as well, the model covers an area of $210 \mathrm{~km}^{2}$ (Salzburg) up to $744 \mathrm{~km}^{2}$ (Vienna). In vertical direction, the model considered from 39 (Vienna) up to 53 (Salzburg and Innsbruck) vertical levels with resolutions varying between 10 and $100 \mathrm{~m}$ with denser grid spacing near surface. Additional vertical domain extensions were necessary for the orographic structured terrains (e.g. high surrounding mountains) of Salzburg and Innsbruck, where 150-m and 200-m-wide levels were also applied on the top of the model layer.

\section{Results}

\subsection{Model validation}

The hourly outputs of high-resolution MUKLIMO_3 3D fields on near-surface level $(2 \mathrm{~m})$ were compared with air temperature and humidity measured at $2 \mathrm{~m}$ height and wind speed and direction measured at $10 \mathrm{~m}$ height at the semiautomatic weather stations, TAWES (GCOS Austrian Inventory Report 2017), of the cities. In addition to the nine official weather stations of the weather service, in Vienna, the measurement network of the city administration responsible for environmental monitoring (Vienna MA22) was also included in the analysis (Table 2). In other cities, much less observational data are available due to the limited number of measurement stations (e.g. in case of Klagenfurt only one), making the analysis of differences between urban and related rural areas much difficult or impossible. The hourly forecasts $(0600+0001$ to $0600+0024$ UTC $)$ of the NWP model ALARO were also considered in the analysis in order to evaluate the benefit of UCM application and to determine model dependences. 
Table 2 Measurement station characteristics (station ID, name, elevation, and land use class) considered in this study. Urban and rural stations for determining UHI intensity are indicated in the column called
UHI urban/rural. Colour code used as background for city names serves as identification during this paper

\begin{tabular}{|c|c|c|c|c|c|}
\hline City & Station & Name & UHI uban/rural & Elevation (m) & Land use \\
\hline \multirow{15}{*}{ Vieruns } & 4015 & WIENJAEGERWIESE & \multirow{9}{*}{ UHI urban } & 453 & 31000 - Forests \\
\hline & 4115 & WIEN/STAMMERSDORF & & 191 & 11220 - Discontinuous medium density uban fabric \\
\hline & 5802 & WIEN-תUBILAEUMSWARTE & & 450 & $31000-$ Forests \\
\hline & 5805 & WIEN-MARIABRUNN & & 225 & 12100 - Industrial commercial, public, military and private unats \\
\hline & 5904 & WIEN-HOHE WARTE & & 198 & 14100 - Green uban areas \\
\hline & 5917 & WIEN/UNTERLAA & & 201 & 12100 - Industrial commercial, public, military and prisate units \\
\hline & 5925 & WIEN.INNERE STADT & & 177 & 11100 - Continuous urban fabric \\
\hline & 5934 & WWIEN-DRESDNERSTRASSE & & 164 & 11100 - Contimuous vaban fabric \\
\hline & 5935 & WIEN-DONAUFELD & & 161 & 12220 - Other rasds and associated land \\
\hline & 5972 & GROSS.ENZFRSDORF & \multirow[t]{6}{*}{ UHI runal } & 154 & 11220 - Discontinuous medium density urban fabric \\
\hline & 5978 & WIEN-DUNKLERGASSE & & 184 & 14100 - Green urben arcas \\
\hline & 5979 & WIEN-UNTFRE LOBAU & & 155 & 31000 - Forests \\
\hline & 5985 & WIEN-AKH-DACH & & 193 & 12100 - Industrial commercial, public, military and private units \\
\hline & 5989 & WIEN-ALBERNERSTRASSE & & 153 & 11220 - Discontinuous medium density urban fabric \\
\hline & 5990 & SCHWECHAT & & 184 & 12400 - Airperts \\
\hline \multirow{3}{*}{ Graz } & 16400 & GRAZ-FLUGHAFEN & \multirow{3}{*}{$\begin{array}{l}\text { UHI rural } \\
\text { UHI urban }\end{array}$} & 337 & $12400-$ Airports \\
\hline & 16412 & GRAZ.UNIVERSITAET & & 366 & 12100 - Industrial commercial, public, military and private units \\
\hline & 16413 & GRAZSTRASSGANG & & 357 & 11220 - Discontinuous modium density urban fabric \\
\hline \multirow{2}{*}{ Linz } & 3202 & LNZ-STADT & UHI urban & 262 & $11100-$ Continuous urban fabric \\
\hline & 5000 & HOERSCHING & UHI rural & 298 & 12400 - Aimperts \\
\hline \multirow{2}{*}{ Salzbarg } & 6300 & SALZBURG-FLUGHAFEN & UHI rural & 430 & $12400-$ Aimerts \\
\hline & 6305 & SALZBURG-FREISAAL & UHI urben & 418 & 12100 - Industrial commercial, public, military and private units \\
\hline \multirow{2}{*}{ Inssbruck } & 11803 & INNSBRUCK-UNIVERSITAET & UHI urben & 578 & 12100 - Industrial commercial, public, military and private units \\
\hline & 11804 & INNSBRUCK FLUOPLATZ & UHI rural & 578 & 12400 - Airports \\
\hline Klagenfiart & 20212 & KLAGENFURT-FLUGHAFEN & & 450 & 12400 - Aiports \\
\hline
\end{tabular}

The model prediction skills for urban areas was evaluated using different methods illustrating a statistical comparison with the observations. The Taylor diagram (Taylor 2001) in Fig. 3 provides aggregated statistics of the Pearson correlation coefficient, standard deviation, and root mean square error for hourly air temperature, humidity, and wind speed. Statistics for air temperature show a slight clustering feature of data from the NWP model compared to the analysed NWP and UCM chain. Although the MUKLIMO_3 model results have better standard deviation scores, they show about $4 \%$ lower correlation ratio (0.90) and slightly larger (2\%) RMSE values with a range from $2.7^{\circ} \mathrm{C}$ (Klagenfurt) up to $3.4^{\circ} \mathrm{C}$ (Vienna) compared to ALARO. Based on the underrepresentation of complex terrain in the ALARO model, the weakest performance was assessed for Innsbruck with the largest RMSE values $\left(4.2^{\circ} \mathrm{C}\right)$ in ALARO, while MUKLIMO_3 had an RMSE of $3.2^{\circ} \mathrm{C}$.

When analysing humidity and wind speed variables, much larger biases and spreads occur. The Pearson correlation coefficients between forecasts and observations of relative humidity are similar for both models (between 0.54 and 0.75 ). In most cases, ALARO provides slightly larger RMSE values for humidity, except for Vienna, where ALARO performs somewhat better. The largest differences (about 20\%) among the models related their RMSE was found in Vienna and Innsbruck. This kind of similarities in performance of humidity prediction were not expected due to the fact that MUKLIMO 3 does not include any precipitation in simulations. In addition, a larger variability can be observed in wind a)

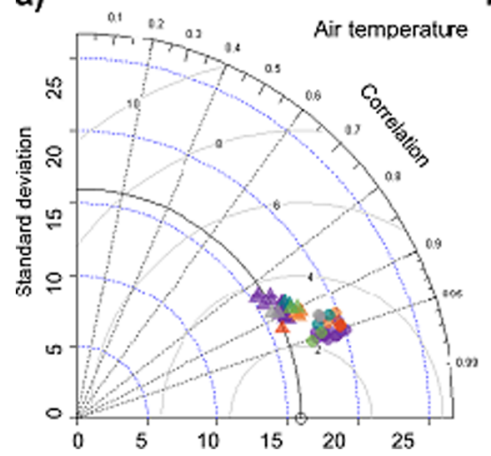

b)

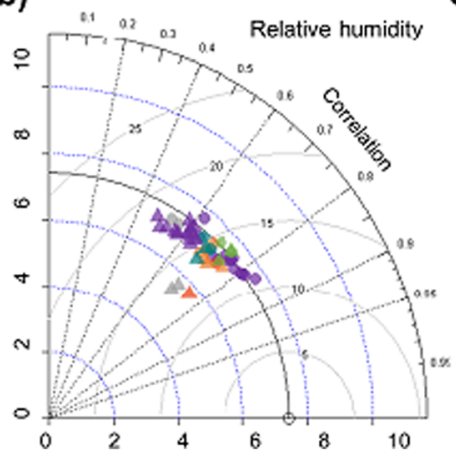

c)

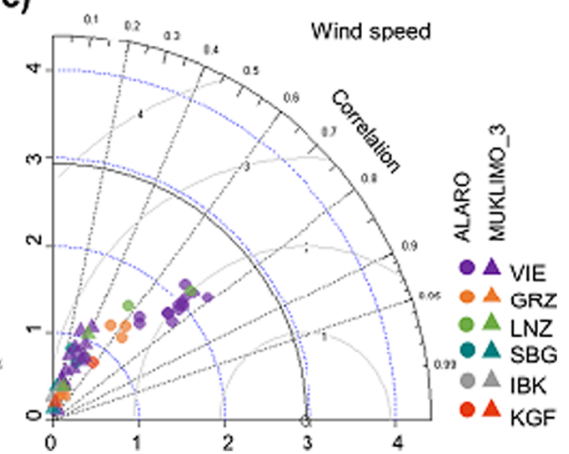

Fig. 3 Taylor diagram for model validation of parameters a hourly air temperature at $2 \mathrm{~m}$ height, $\mathbf{b}$ relative humidity at $2 \mathrm{~m}$ height, and $\mathbf{c}$ wind speed at $10 \mathrm{~m}$ height over the summer period of 2019 (1 April-31 October). The Pearson correlation coefficient (azimuthal scale), standard deviation (radial distance), and root mean square error (proportional distance from the point on the $\mathrm{x}$-axis identified as "observed" (grey circle)) are illustrated. Triangles and circles indicate the performance of MUKLIMO_3 and ALARO model simulations, respectively, while colours refer to the measurement stations located in different cities 
speed. MUKLIMO_3 performed wind speed predictions with a correlation ratio of 0.05 (Innsbruck) up to 0.42 (Vienna and Linz), while ALARO has slightly larger coefficients from 0.06 (Salzburg) up to 0.53 (Linz). The best Pearson correlation and RMSE statistics of MUKLIMO 3 were provided for the reference stations of the cities in case of air temperature and relative humidity parameters.

The box-and-whisker diagram (Fig. 4) for the hourly differences between modelled and observed atmospheric parameters graphically represent the overall range of the data, the median, and distribution of the data in different quartiles. The models have similar performance characteristics; however, MUKLIMO_3 has somewhat larger mean biases and in most cases larger variability and spread compared to ALARO. The warmer air temperature bias for both simulations is primarily due to an overestimation of nighttime air temperatures. Apart from air temperature statistics for the stations in Innsbruck, where the sign of the bias also differs, the median of the bias in MUKLIMO 3 is around $0{ }^{\circ} \mathrm{C}$. The model performance for the parameter relative humidity is similar for both models. Considering the parameter wind speed at 10-m height, MUKLIMO_3 underestimates the hourly values in general, while ALARO performance varies between each station.

The variation of MUKLIMO_3 model biases was analysed based on the Urban Atlas LU classification scheme, where the measurement stations are located. The results for air a)

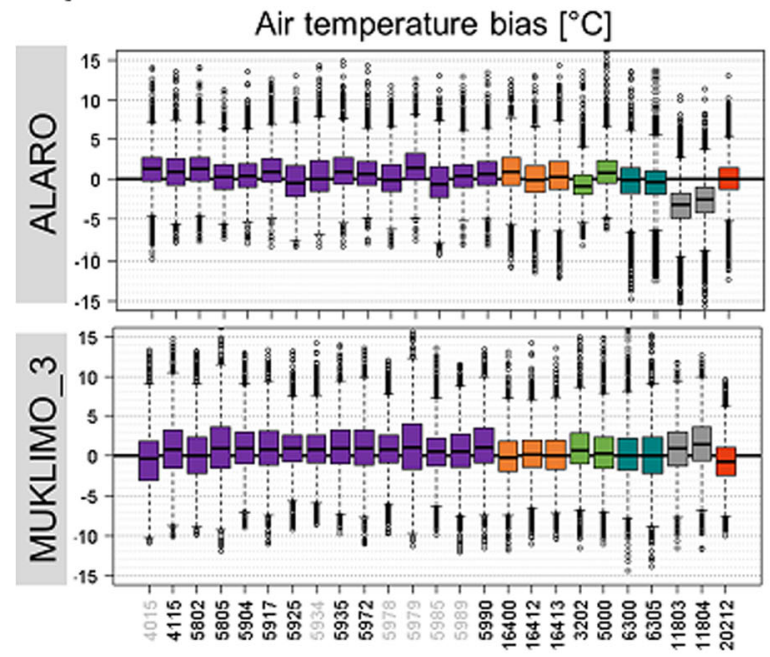

b)

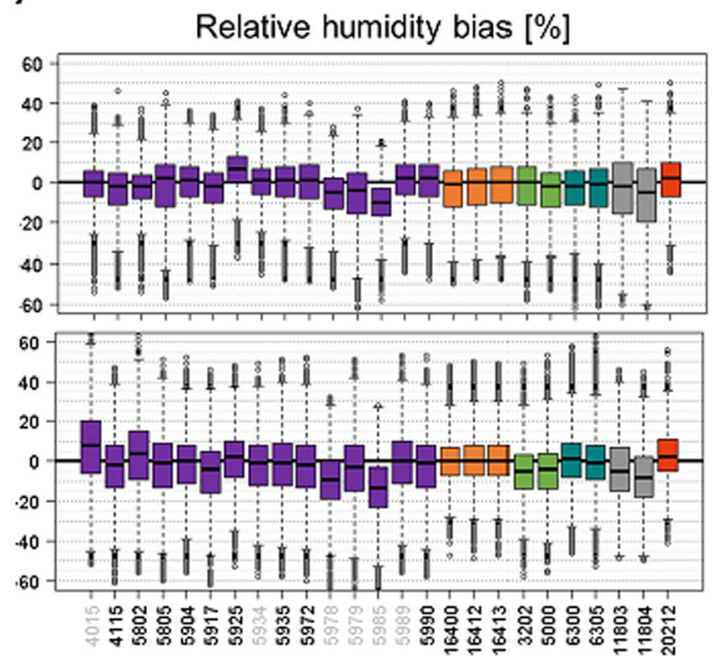

c)

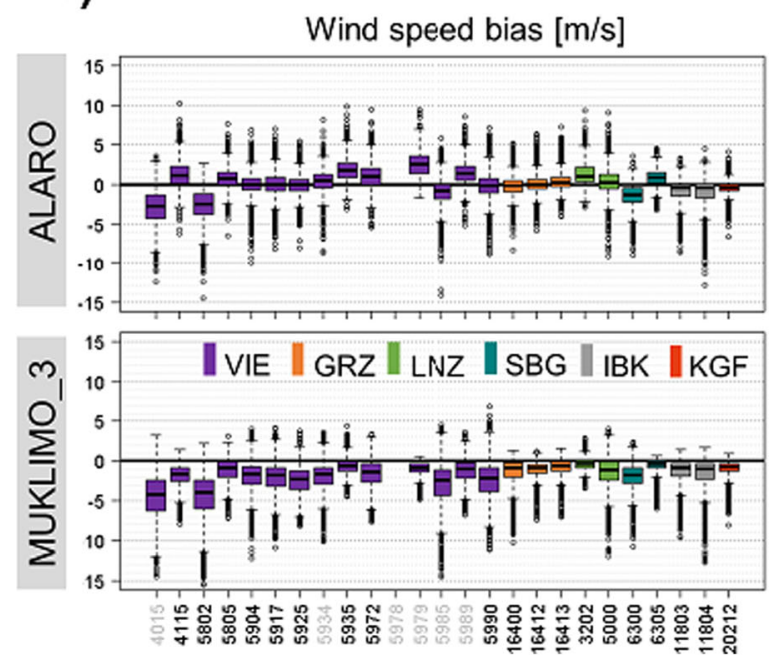

Fig. 4 ALARO and MUKLIMO_3 model derived box-and-whisker diagram for validation of parameters a hourly air temperature at 2-m height, b relative humidity at 2-m height, and $\mathbf{c}$ wind speed at $10-\mathrm{m}$ height over the summer period of 2019 (1 April-31 October) compared to the hourly observations of the measurement stations (x-axis). The height of the box is given by the interquartile range of the dataset and extends from the 25 th to 75 th percentile. The horizontal bar within the box denotes the median value. The ends of the whiskers are drawn to the 10th and 90th percentile values. Station ID in grey indicate the measurement stations of the city administration. Station ID and corresponding colour codes are described in Table 2 
temperature and relative humidity in Fig. 5 indicate similar model performance for all LU classes. The smallest bias spread and range for all parameters were found for the LU 12 (airports), which in most cities (Graz, Linz, Salzburg, Innsbruck, Klagenfurt) are locations of the reference stations for the UCM simulations. The largest biases occur in forested areas, especially for the parameter wind speed, where two out of three stations located in forests are possibly not in accordance with the WMO standards

While the mesoscale model in most cases underestimates the lower temperatures and overestimates the higher ones, MUKLIMO_3 shows different performance (Fig. 6). It systematically overestimates low temperatures but fits the observations of extreme high temperature values well. Considering the parameter relative humidity, especially at stations located in forested areas, both models show similarly strong overestimations of low humidity conditions and underestimate by higher humidity content (over 60-65\%).

In order to analyse possible hourly variation of bias, the cumulated hourly absolute errors are shown in the heatmap diagram (Fig. 7). The warm mean temperature bias for MUKLIMO_3 simulations is overestimated mainly due to the nighttime air temperatures. Even though MUKLIMO_3 simulations produce relatively low biases for air temperature in the first $4-5 \mathrm{~h}$ of simulation $\left(0.75-2.0^{\circ} \mathrm{C}\right.$ apart from forested areas), much larger differences occur over time. ALARO performs differently and has its larger biases (1.25$4.0^{\circ} \mathrm{C}$ ) during daytime, when maximum temperature is normally reached. Relative humidity predictions appear to be much less plausible and show large variety in model prediction skills.

Using a confusion matrix (Fig. 8) for classification evaluation, the number of correct and incorrect MUKLIMO_3 and ALARO predictions of two air temperature thresholds (summer and hot days - days with temperatures equal or greater than $25^{\circ} \mathrm{C}$ and $30^{\circ} \mathrm{C}$, respectively) for the inner-city stations of the analysed cities was evaluated. The overall performance of the MUKLIMO_3 model was good, the UCM achieved better results for hot days compared to summer days. In accordance with previous statements, the NWP largely overestimates the maximum temperatures in cities (false positive), while MUKLIMO_3 rather underestimates the threshold exceedences (false negative). The largest differences of forecast skills happened in Vienna and Klagenfurt. Observations from 2019 show that all cities were affected by extreme heat periods. Hot conditions prevailed in Vienna over 45 days, in Graz and Innsbruck both over 33 days, in Klagenfurt over 29 days, while in Linz and Salzburg over 22 days. This corresponds to a correctly forecasted ratio of $73 \%, 63 \%, 55 \%$, $55 \%, 33 \%$, and $8 \%$ for Vienna, Graz, Linz, Salzburg, Innsbruck, and Klagenfurt, respectively, for hot days modelled by MUKLIMO_3. For summer days, this ratio is significantly better, being $90 \%, 78 \%, 86 \%, 61 \%, 57 \%$, and $52 \%$ for the same order of cities. Even though in some cases the NWP show higher performance statistics, due to other factors (e.g. model resolution, representation of urban characteristics, and lacking physical processes), the model is not appropriate for intra-urban analysis, as well as being too coarse to record the variability of microscale climate.

The hourly variations and frequency of UHI intensity during the summer period 2019 are shown in Fig. 9 illustrating also the median and the 10th and 90th percentiles of cumulative hourly frequency distributions based on calculated urbanrural differences using the measurements and modelled air temperature values at the stations in the city centre and the reference. The UHI intensity is defined as the difference of hourly air temperature measurements at 2-m height between the urban and rural station (urban and rural stations are indicated in Table 2, and the location is indicated in Fig. 1b). Due to a missing station located in urban areas, the city a)

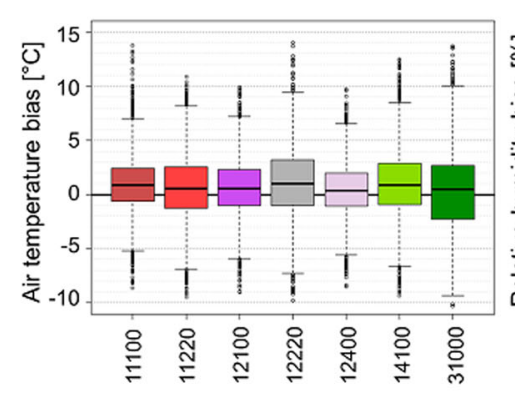

b)

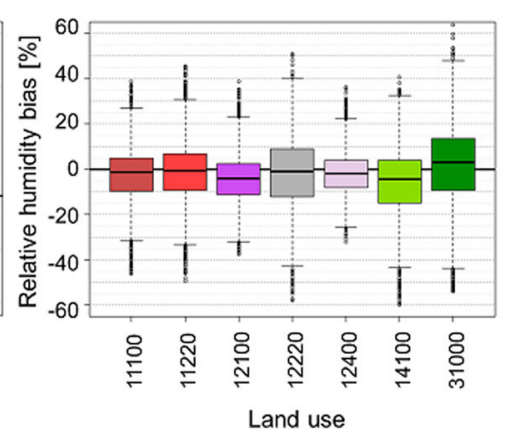

c)

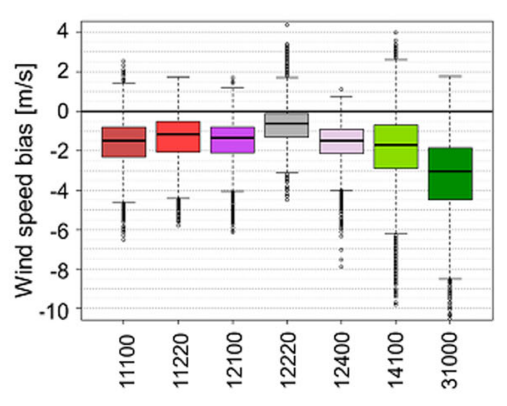

Fig. 5 MUKLIMO_3 model derived box-whisker diagram for validation of parameters a hourly air temperature at $2-\mathrm{m}$ height, $\mathbf{b}$ relative humidity at 2-m height, and $\mathbf{c}$ wind speed at $10 \mathrm{~m}$ height over the summer period of 2019 (1 April-31 October). It illustrates the relative bias of MUKLIMO 3 hourly model outputs compared to the observations of the measurement stations (Table 2) per Urban Atlas land use classes. The height of the box is given by the interquartile range of the dataset and extends from the 25th to 75 th percentile. The horizontal bar within the box denotes the median value. The ends of the whiskers are the 10th and 90th percentile values 

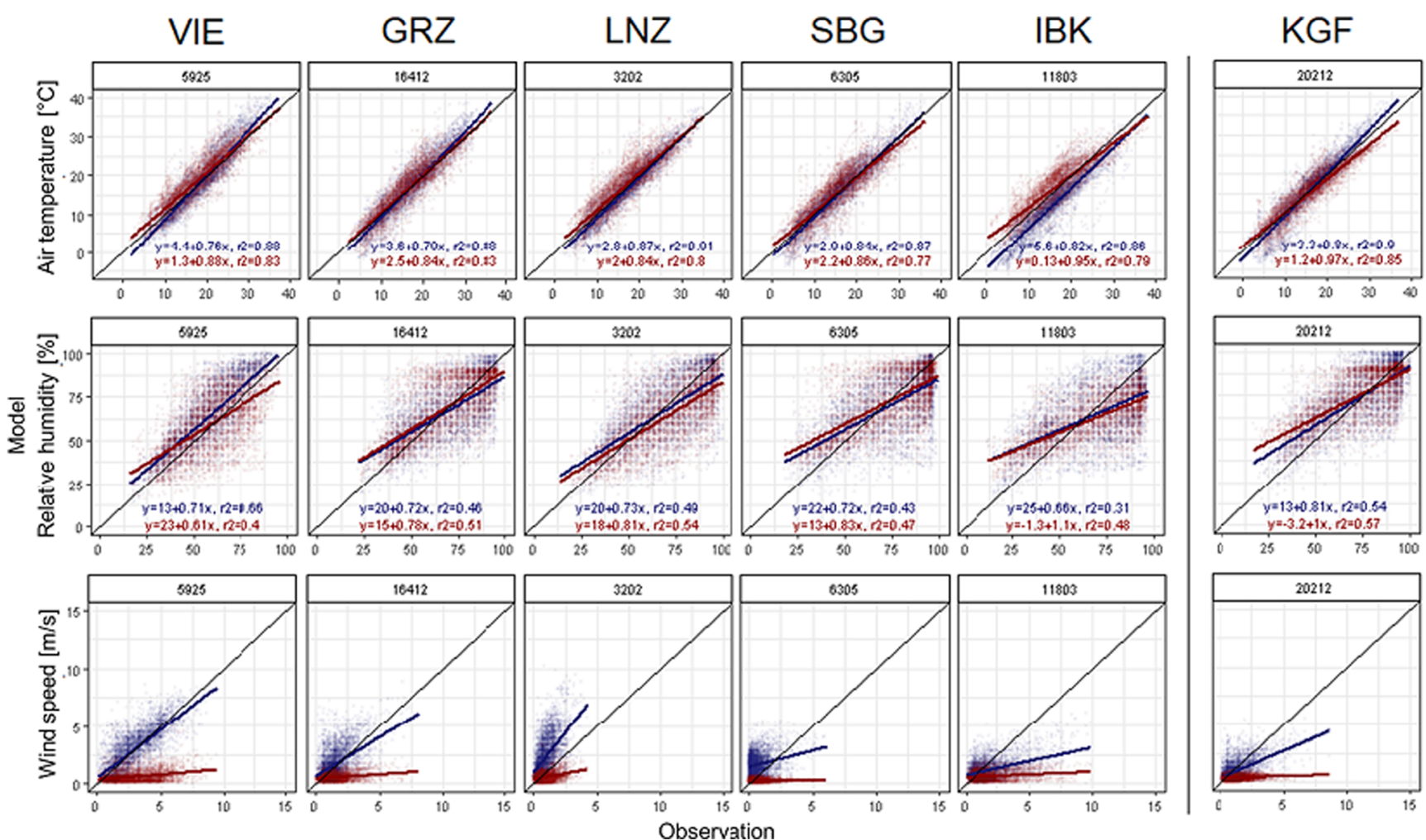

Fig. 6 Scatter and quantile-quantile plot of modelled (y-axis) and ob-

Salzburg, and Innsbruck and for the only (rural) station in Klagenfurt served (x-axis) hourly values of air temperatures at 2-m height (first row), relative humidity at $2-\mathrm{m}$ height (second row), and wind speed at 10-m height (third row) for the urban stations of Vienna, Graz, Linz, for validation purposes. Blue and red circles and lines indicate results for ALARO and MUKLIMO_3, respectively

a)

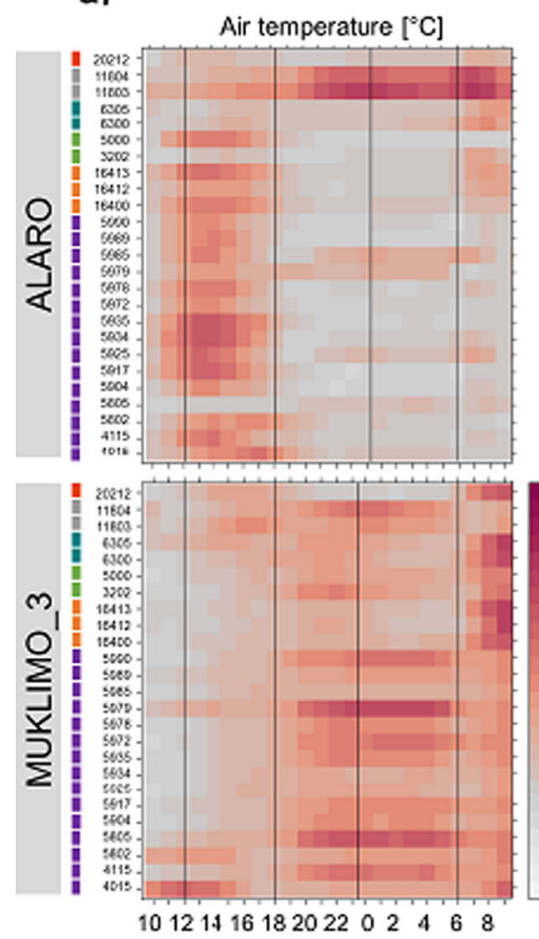

b)
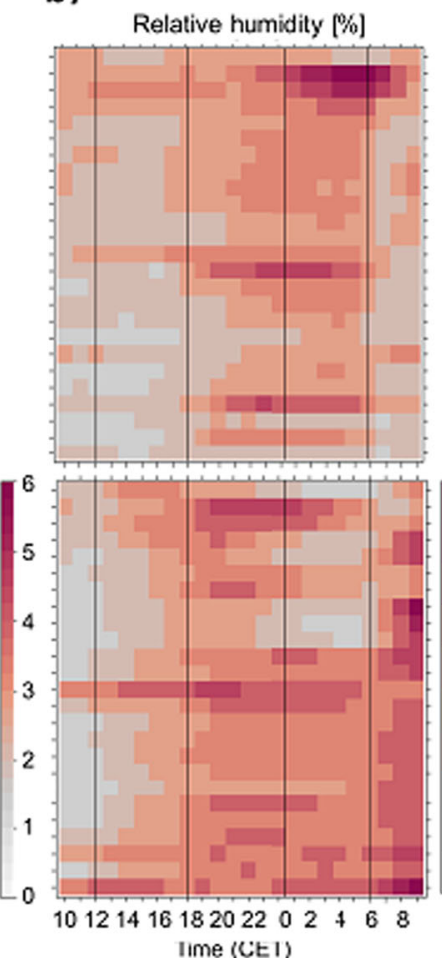

c)
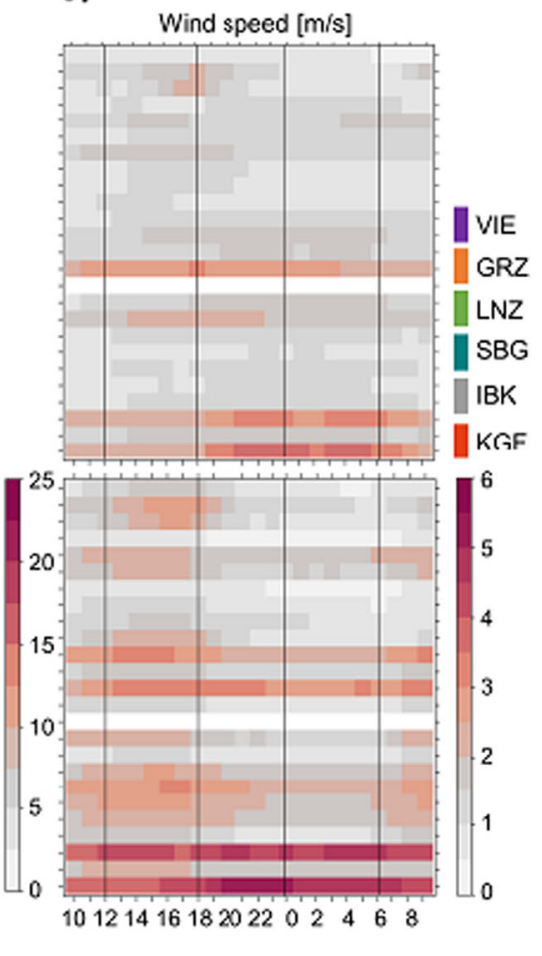

Fig. 7 Heatmap of multi-hour biases of a air temperature at 2-m height, $\mathbf{b}$ relative humidity at 2-m height, and $\mathbf{c}$ wind speed at 10-m height in ALARO and MUKLIMO_3 models compared to the measurements at the observation stations 


\section{MUKLIMO_3}

Summer days $\left(T_{\max } \geq 25^{\circ} \mathrm{C}\right)$
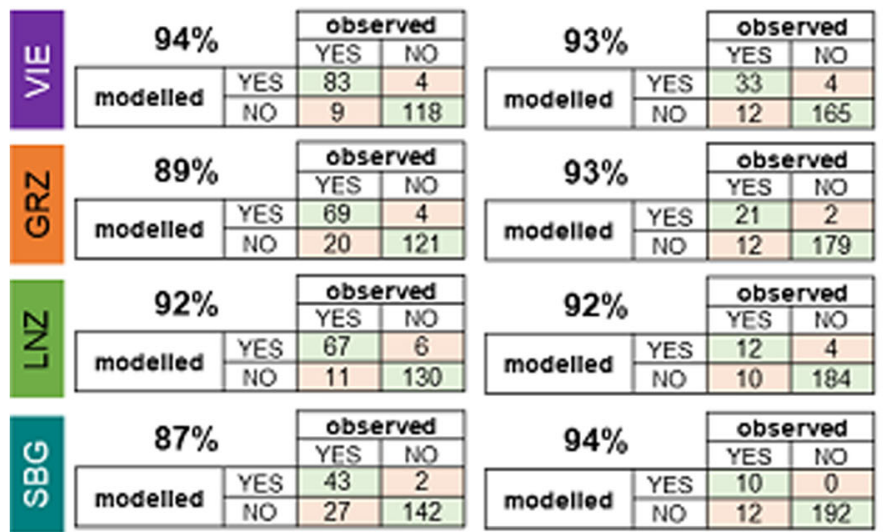

\begin{tabular}{|c|c|c|c|}
\cline { 3 - 4 } \multicolumn{1}{c|}{} & \multicolumn{2}{c|}{ observed } \\
\cline { 3 - 4 } \multicolumn{2}{c|}{} & YES & NO \\
\hline \multirow{2}{*}{ modelled } & YES & 10 & 0 \\
\cline { 2 - 4 } & NO & 12 & 192 \\
\hline
\end{tabular}
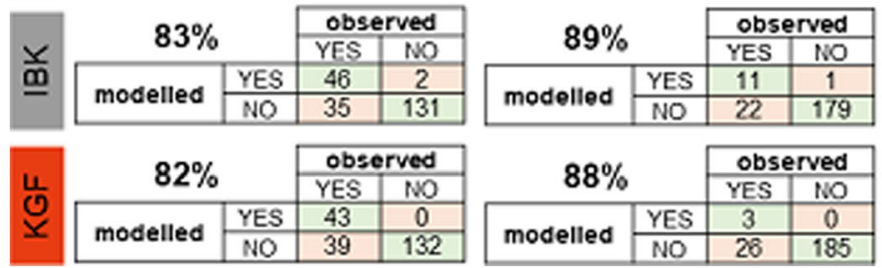

\begin{tabular}{|c|c|c|c|}
\cline { 3 - 4 } \multicolumn{2}{c|}{} & \multicolumn{2}{|c|}{ Observed } \\
\cline { 3 - 4 } \multicolumn{2}{c|}{$88 \%$} & YES & NO \\
\hline \multirow{2}{*}{ modelled } & YES & 3 & 0 \\
\cline { 2 - 4 } & NO & 26 & 185 \\
\hline
\end{tabular}

Fig. 8 Confusion matrix for daily maximum air temperature thresholds $\left(\mathrm{T}_{\max } \geq 25^{\circ} \mathrm{C}\right.$ and $\mathrm{T}_{\max } \geq 30{ }^{\circ} \mathrm{C}$ ) in the summer season 2019 (from April 1 to October 31) for the urban stations of cities (except Klagenfurt, where the only station in rural area is shown) to evaluate the forecast quality of

of Klagenfurt was excluded from this validation analysis. Generally, MUKLIMO_3 underestimates the UHI intensity in Vienna and Innsbruck and has a smaller spread in all cities (Fig. 9b). The period considered in this analysis (1 April-31 October) was characterized by varying synoptic and mesoscale forcing, but considering air temperature, the season was far above the long-term climate average. April 2019, one of the 25 warmest months in the measurement history in Austria was followed by a quite cold May. In most of Austria, it was for the first time in around 30 years a May without a summer days - in Klagenfurt, the first time since 1989, in Salzburg and Linz since 1991, while Graz and Vienna had only 2 summer days compared to the monthly average of 6 . The summer 2019 came close to the record of summer 2003; June 2019 was the warmest, sunniest, and driest in the measurement history of Austria, about $4.7^{\circ} \mathrm{C}$ above the climate average. The number of hot days was about two or three times higher than in the climate normal period 1981-2010. The shape of this monthly variability is also reflected in the UHI intensities (Fig. 9a, c), apart from the results in Salzburg that had a maximum in April and low variability over the remaining period. The simulations follow this development only to a certain degree. In the cities, Vienna and Innsbruck a uniform underestimation of UHI intensity can be observed over months, whereas in Linz and Graz MUKLIMO_3 simulates larger urban-rural differences than observed. Apart from

\begin{tabular}{|c|c|c|c|c|c|c|c|}
\hline \multicolumn{8}{|c|}{ ALARO } \\
\hline \multicolumn{4}{|c|}{ Summer days $\left(T_{\max } \geq 25^{\circ} \mathrm{C}\right)$} & \multicolumn{4}{|c|}{ Hot days $\left(T_{\max } \geq 30^{\circ} \mathrm{C}\right)$} \\
\hline \multirow{2}{*}{\multicolumn{2}{|c|}{$87 \%$}} & \multicolumn{2}{|c|}{ observed } & \multirow{2}{*}{\multicolumn{2}{|c|}{$85 \%$}} & \multicolumn{2}{|c|}{ observed } \\
\hline & & YES & NO & & & YES & No \\
\hline \multirow{2}{*}{ modelled } & YES & 90 & 26 & \multirow{2}{*}{ modelled } & YES & 45 & 32 \\
\hline & NO & 2 & 96 & & NO & 0 & 137 \\
\hline \multirow{2}{*}{\multicolumn{2}{|c|}{$89 \%$}} & \multicolumn{2}{|c|}{ observed } & \multirow{2}{*}{\multicolumn{2}{|c|}{$87 \%$}} & \multicolumn{2}{|c|}{ observed } \\
\hline & & YES & NO & & & YES | & NO \\
\hline \multirow{2}{*}{ modelled } & YES & 83 & 18 & \multirow{2}{*}{ modolled } & YES & 27 & 20 \\
\hline & NO & 6 & 107 & & NO & 6 & 161 \\
\hline \multirow{2}{*}{\multicolumn{2}{|c|}{$92 \%$}} & \multicolumn{2}{|c|}{ observed } & \multirow{2}{*}{\multicolumn{2}{|c|}{$87 \%$}} & \multicolumn{2}{|c|}{ observed } \\
\hline & & YES & NO & & & YES | & NO \\
\hline \multirow{2}{*}{ modelled } & YES & 73 & 11 & \multirow{2}{*}{ modelled } & YES & 12 & 12 \\
\hline & NO & 5 & 125 & & NO & 7 & 176 \\
\hline \multirow{2}{*}{\multicolumn{2}{|c|}{$89 \%$}} & obst & ved & \multirow{2}{*}{\multicolumn{2}{|c|}{$95 \%$}} & obs & rved \\
\hline & & YES & NO & & & YES & NO \\
\hline \multirow{2}{*}{ modelled } & YES & 59 & 11 & \multirow{2}{*}{ modelled } & YES & 17 & 6 \\
\hline & NO & 11 & 133 & & NO & 5 & 186 \\
\hline \multirow{2}{*}{\multicolumn{2}{|c|}{$81 \%$}} & obst & ved & \multirow{2}{*}{\multicolumn{2}{|c|}{$88 \%$}} & obs & rved \\
\hline & & YES & NO & & & YES & NO \\
\hline \multirow{2}{*}{ modelled } & YES & 43 & 1 & \multirow{2}{*}{ modelled } & YES & 10 & 0 \\
\hline & NO & 38 & 132 & & NO & 22 & 180 \\
\hline \multirow{2}{*}{\multicolumn{2}{|c|}{$93 \%$}} & obst & ved & $02 \%$ & & obs & rved \\
\hline & & YES & NO & $92 \%$ & & YES & NO \\
\hline modelled & YES & 76 & 8 & & YES & 24 & 11 \\
\hline modelled & NO & 6 & 124 & modelled & No & 5 & 174 \\
\hline
\end{tabular}

MUKLIMO_ 3 and ALARO models. The green marked places stand for the correctly predicted or correctly unpredicted summer and hot days. Percentage values indicate the overall correct predicted thresholds

Salzburg, in all cities the largest UHI intensities are measured during night (Fig. 9d). The minor UHI intensity in case of Salzburg might be explained by the location of the measurement stations: Salzburg Airport, as well as the area of Salzburg Freisaal, represents characteristics of rural regions and is therefore less suitable for demonstrating differences between densely built-up and surrounding areas. This feature is underlined by the observations, as well as in the model results in form of a lacking UHI effect during night. Compared to other cities, the distance between the urban and rural stations in Innsbruck is relatively small (about $2.5 \mathrm{~km}$ distance) characterized by medium-density urbanized area and being exposed to the main channelized wind direction, which might contribute to the underrepresentation of UHI. In some cases, the observations show a second peak in morning hours, which is more pronounced in MUKLIMO_3 simulations. The largest UHI intensities in summer 2019 were measured in Vienna that were not reflected by the model simulations; however, the shape of 90th percentiles fits the observations quite well.

\subsection{Intra-urban UHI effects over the summer period 2019}

The UHI effect can vary significantly in space and time. Heterogeneities can be explained by orography effects, by differences of surface properties, morphology, or human 

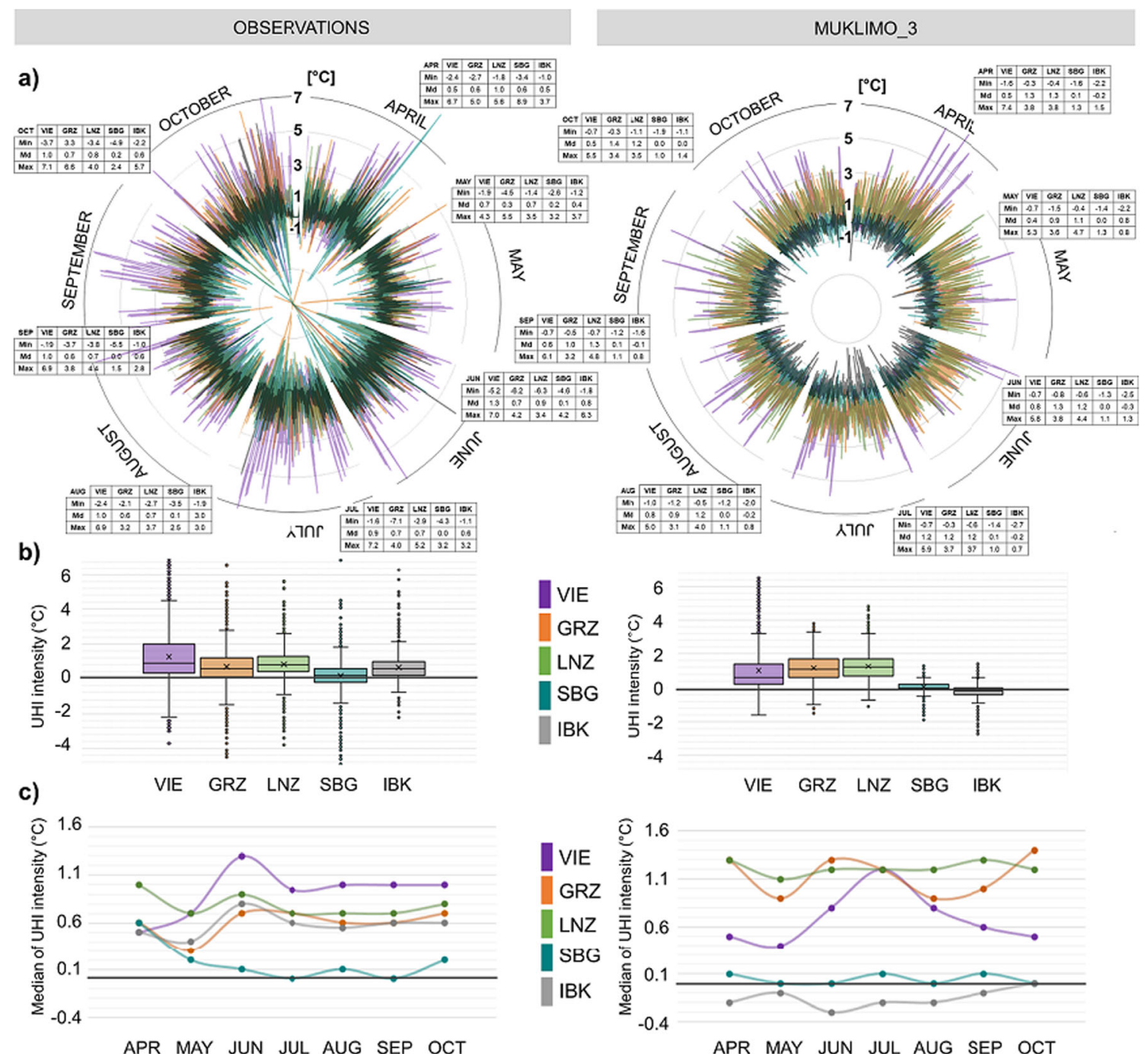

d)
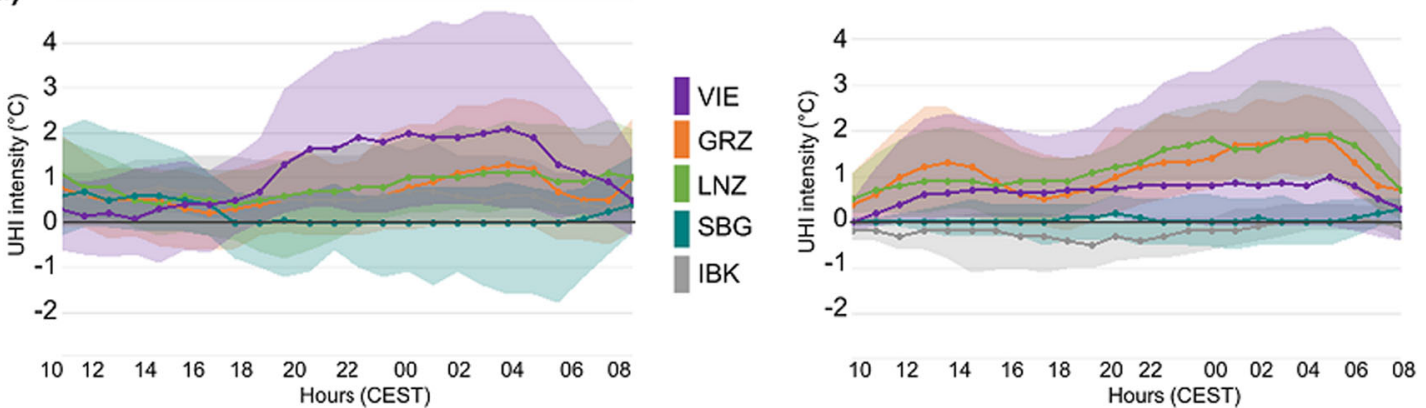

Fig. 9 Observed and modelled UHI intensities (differences of hourly air temperature at 2-m height between the urban and rural station) for Vienna, Graz, Linz, Salzburg, and Innsbruck in the study period (1

April - 31 October 2019) using a time series, b box-whisker diagram (black within the box marks the mean value), $\mathbf{c}$ monthly time series of the UHI intensity median, and $\mathbf{d}$ multi-hour urban-rural differences

activities. Particularly important for heat warning systems are the extreme values of air temperature and relative humidity. Figure 10 shows the mean difference of maximum air temperature and mean relative humidity compared to the reference stations in each city, illustrating intra-urban variability that is strongly linked to building and impervious characteristics, as well as green surface fractions. The largest differences in

maximum air temperatures simulated by MUKLIMO_3 were found in the most urbanized part of the cities and reached an extent of $3.0{ }^{\circ} \mathrm{C}$ in Graz, followed by Klagenfurt $\left(2.3{ }^{\circ} \mathrm{C}\right)$, $\operatorname{Linz}\left(2.1^{\circ} \mathrm{C}\right)$, Salzburg $\left(2.0^{\circ} \mathrm{C}\right)$, Innsbruck, and Vienna (both $1.5^{\circ} \mathrm{C}$ ) as shown in Fig. 10a. Considering relative humidity pattern, a lack of humidity in the air above the cities in relation to air above surrounding natural environments can be 
a)

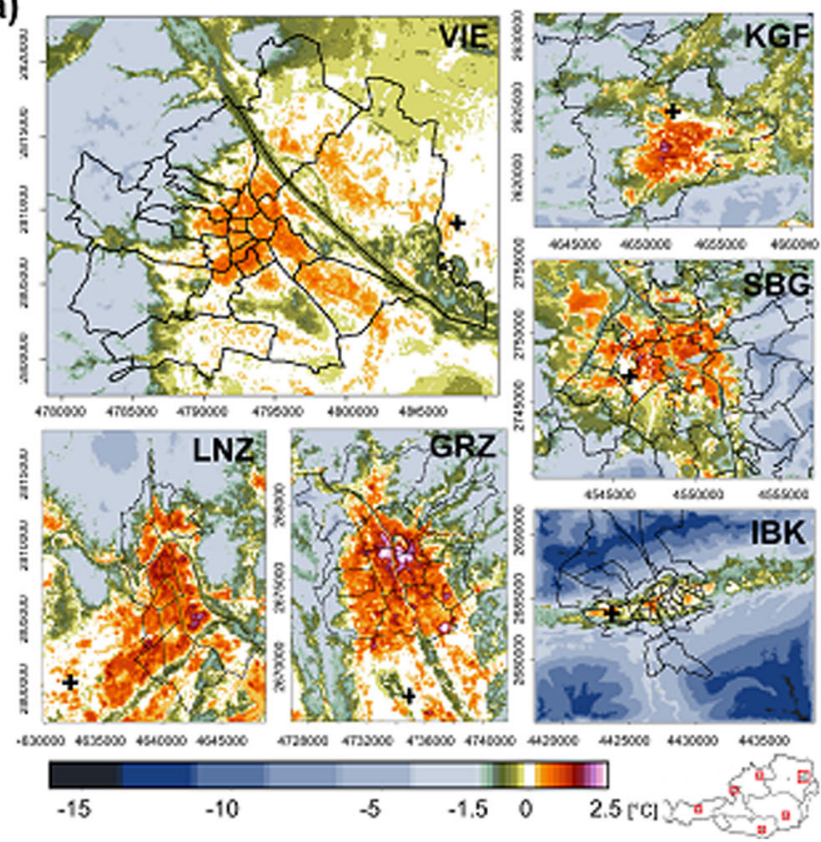

b)

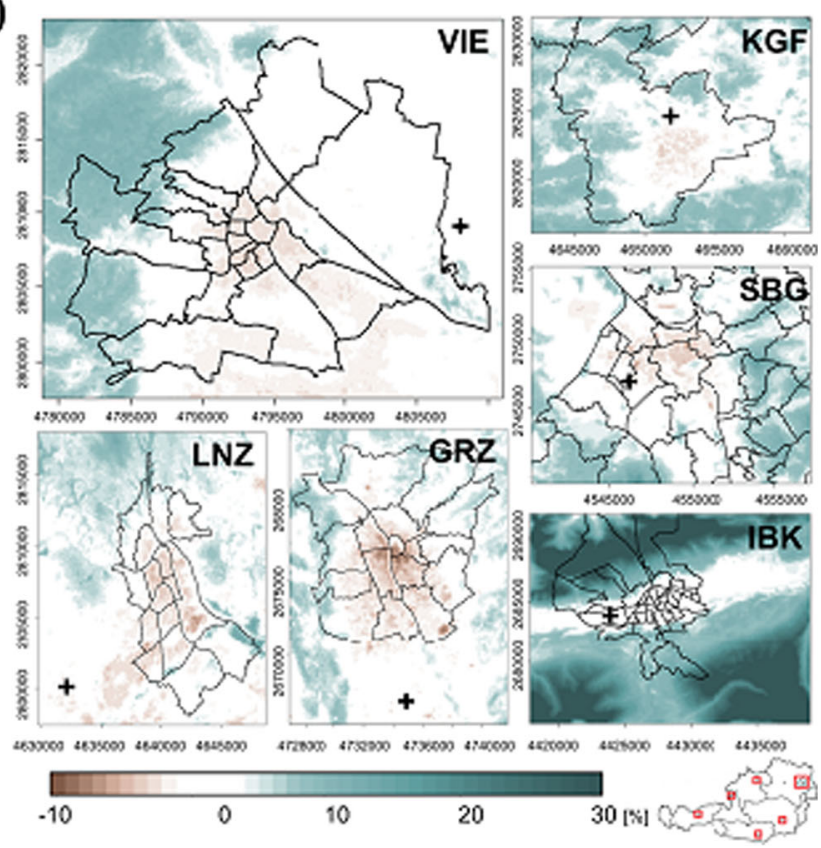

Fig. 10 Difference of a maximum air temperature and $\mathbf{b}$ relative humidity daily means compared to the reference station of each city over the whole period (1 April-31 October 2019) simulated by the MUKLIMO 3 model

observed. This phenomenon is the so-called urban dryness island mentioned already in a study of Hilberg from 1978. Differences of relative humidity over the model simulation domain have a range of -8 to $+11 \%$ in Graz, -4 to $+14 \%$ in Klagenfurt, -6 to $+13 \%$ in Linz, -6 to $+20 \%$ in Salzburg, -2 to $+36 \%$ in Innsbruck, and -5 to $+15 \%$ in Vienna (Fig. 10b).

Figure 11 depicts the mean air temperature over the analysed period. For all the study areas, the hottest and driest zones are the densely built-up areas (LU1/11100, continuous urban fabric with a sealing level over $80 \%$, and LU2/11210, discontinuous dense urban fabric with 50 up to $80 \%$ of soil sealing), directly followed by all zones linked to industrial functions (LU7/12100, industrial, commercial, public, military, and private units) and other (mostly) sealed areas (e.g. transit roads, railways, or airports). A significant drop in both, temperature and humidity, is observed between LU classes that corresponds to the increase in vegetation cover and higher sky view factors, especially in the cities Graz, Linz, Salzburg, Klagenfurt, and Innsbruck. In the latter case, differences and large spreads in LU categories are partly affected by orographic effects (e.g. LU23/31000, forests; LU24/32000, herbaceous vegetation associations) as well. Vegetated areas contribute to a reduction in the local air temperatures (and the UHI effect) by evapotranspiration during daytime. The hottest areas (LU1/ 11100) in cities are on average $1.5^{\circ} \mathrm{C}$ warmer compared to the average air temperature in other zones. Considering mean temperatures over the analysed period, natural areas are 0.5 to almost $2.0^{\circ} \mathrm{C}$ cooler than the average air temperature, while in case of maximum temperature, this difference is much larger.

\subsection{Case study of a 1-day simulation on 26 June 2019}

End of June 2019, an extreme heatwave intensified over central Europe, setting several new monthly air temperature records in neighbouring countries. A hot day, 26 June 2019, was selected to demonstrate relevant UHI influence factors, diverse limitations, and uncertainties but also potentials of the NWP and UCM chain in possible applications. The MUKLIMO_3 model was initiated, as described in Section 2.3, with ALARO analysis fields and was examined for the 1-day simulation. Vertical profiles of temperature showed stable weather conditions in almost all cities; however, a slight temperature inversion $\left(+0.17^{\circ} \mathrm{C} / 100 \mathrm{~m}\right)$ was characteristic in Linz in the lowest $1000 \mathrm{~m}$. This atmospheric boundary layer was rather dry (10-40\%), especially in Innsbruck, where the near-surface humidity decreased already below 50\%. The 0600 UTC fields received from the NWP model were quite accurate, however not representative for the daily conditions. While the initial conditions for the 1D model fitted the observations in Graz, Klagenfurt, and Linz, a slight (calm conditions instead of light breeze) bias for the wind speed was found in Innsbruck and Salzburg. Largest differences were formed in Vienna, where the simulations were started with moderate wind velocity $(5.5 \mathrm{~m} / \mathrm{s})$, resulting in strong streaming patterns over the entire simulation time. The mesoscale wind pattern changing in the afternoon hours in the case of Klagenfurt, Linz, and Salzburg was not implemented in the model. In almost all cities, cloudless conditions prevailed in the morning hours. In Innsbruck, the total cloudiness reached $25 \%$ that was considered as invariable during 
Fig. 11 Modelled mean values of a daily maximum air temperature and $\mathbf{b}$ relative humidity by Urban Atlas land use categories over the analysed period (1 April-31 October 2019) simulated by MUKLIMO 3 using violin plot. Similar to a box plot, the violin plot also shows summary statistics such as median and interquartile ranges. It also indicates the probability density of the data at different values, smoothed by a kernel density estimator a)
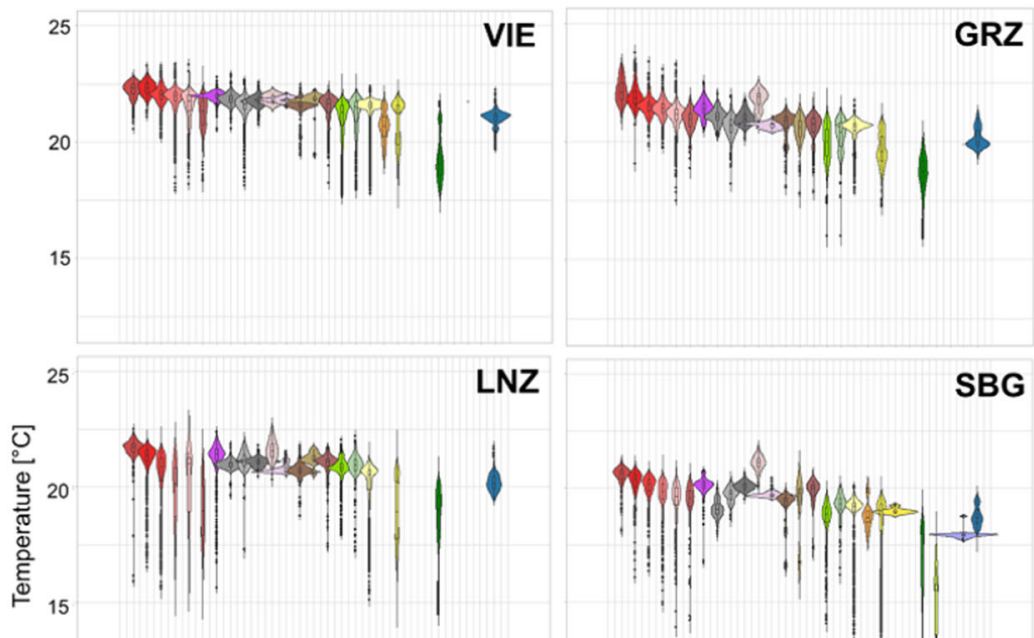

25

IBK

KGF

20

15

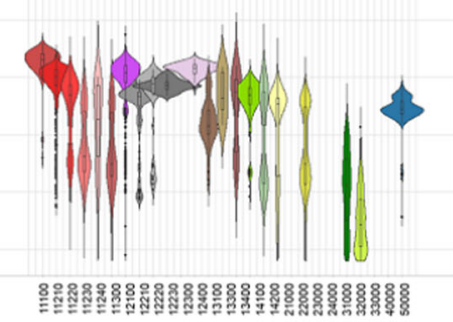

Land use classes

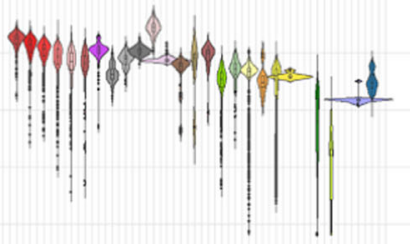

b)

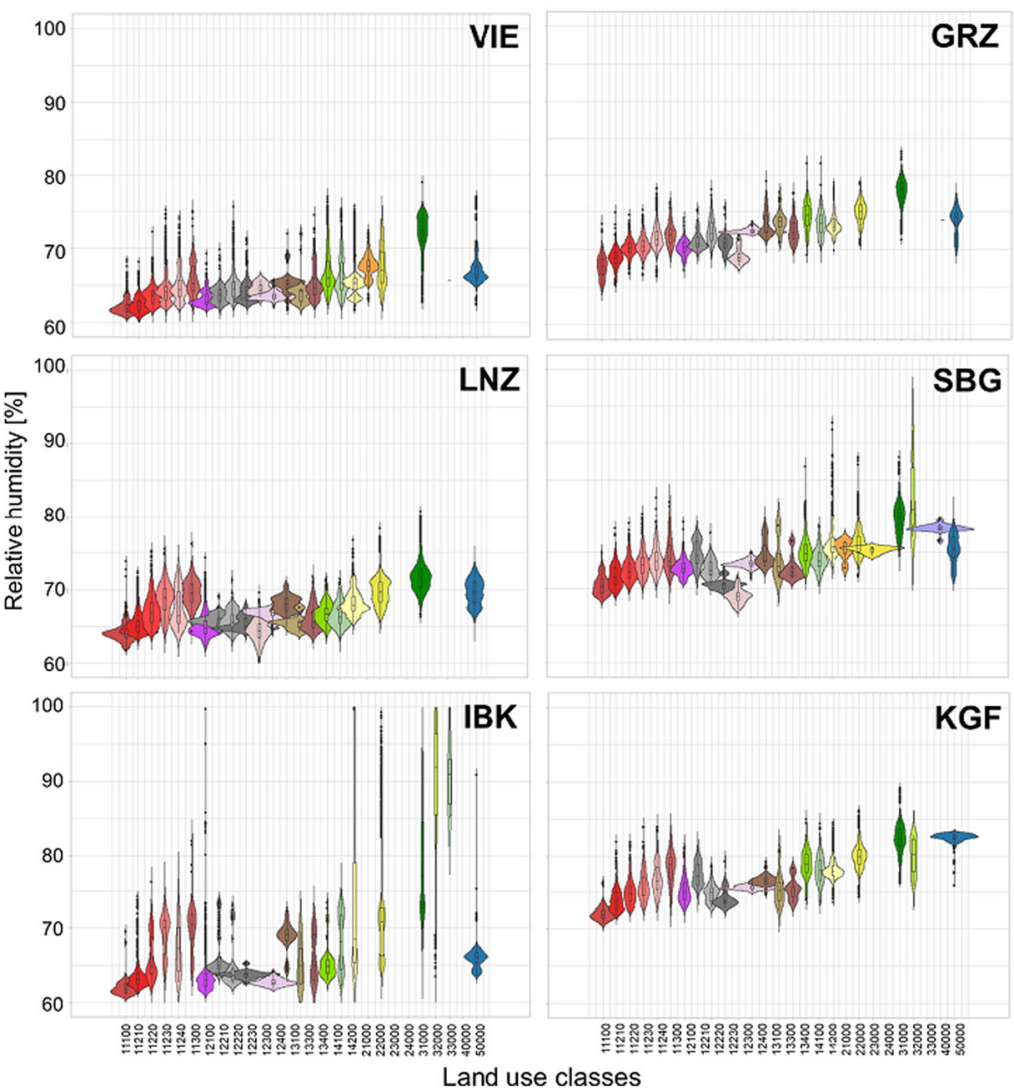


the MUKLIMO 3 simulation, affecting radiation parameters and thereby the daily temperature variability.

The two following figures show the daily cycle of observed and measured air temperatures (Fig. 12) and the spatial distribution of air temperature (Fig. 13) on the selected day. For the LU-based probability density plots, see Appendix (Fig. 14). While the mesoscale model, ALARO extremely overestimated the daily air temperatures (apart from Innsbruck between 5.7 and $10.0{ }^{\circ} \mathrm{C}$ ) in most cities, MUKLIMO_3 predicted this variable with much higher accuracy demonstrating the benefit of applying UCM for heat prediction. Similar performance was observed during other highpressure weather situations, where ALARO forecasted unrealistic high maximum air temperature values for urban areas. Nevertheless, previous statements regarding lacking reproducibility of nocturnal cooling effects in MUKLIMO_3 can be verified here as well. In Klagenfurt, a reversed situation occurred this time (large negative air temperature bias during daytime) that can be explained by a changing wind pattern that was not considered in MUKLIMO_3 anymore but affecting the statistical evaluation positively by chance. Observations here show a similar UHI shape as the statistics over the 7month period (see Fig. 9d), with a maximum UHI intensity of $7.0^{\circ} \mathrm{C}$ in Vienna during nigh. However, due to initiated strong wind speed, the UCM did not capture this effect at all. This also indicates the high sensibility of the UCM on initial conditions, as well as uncertainties in case of high or above average wind situations in the model performance. The simulated windy and well-mixed atmospheric layer conditions in Vienna had also an impact on the LU variability, ending in very similar, LU independent air temperatures. The analysis of LU statistics show larger variability over day; however, a clear difference between built-up and natural areas remains. In addition to the aforementioned findings based on Fig. 11, the variation of air temperature over water surfaces is considerably high despite of the homogeneous initial water surface temperatures in the cities.

\section{Discussion and conclusions}

In this study, the urban climate model MUKLIMO_3 was coupled to the numerical weather prediction model ALARO in order to analyse the performance of UHI prediction skills on hourly based values in the summer period of 2019. Although the six largest cities of Austria, Vienna, Graz, Linz, Salzburg, Innsbruck, and Klagenfurt, affected by different meteorological and climatological conditions due to the Alps, were included in the analysis, the cities also differ in terms of topographic features (e.g. geographic location, influence of natural environment like mountains, water areas) and urban characteristics (e.g. city size, urban morphology). The 100-m horizontal resolution model simulations were compared to empirical data obtained from the traditional monitoring network of ZAMG
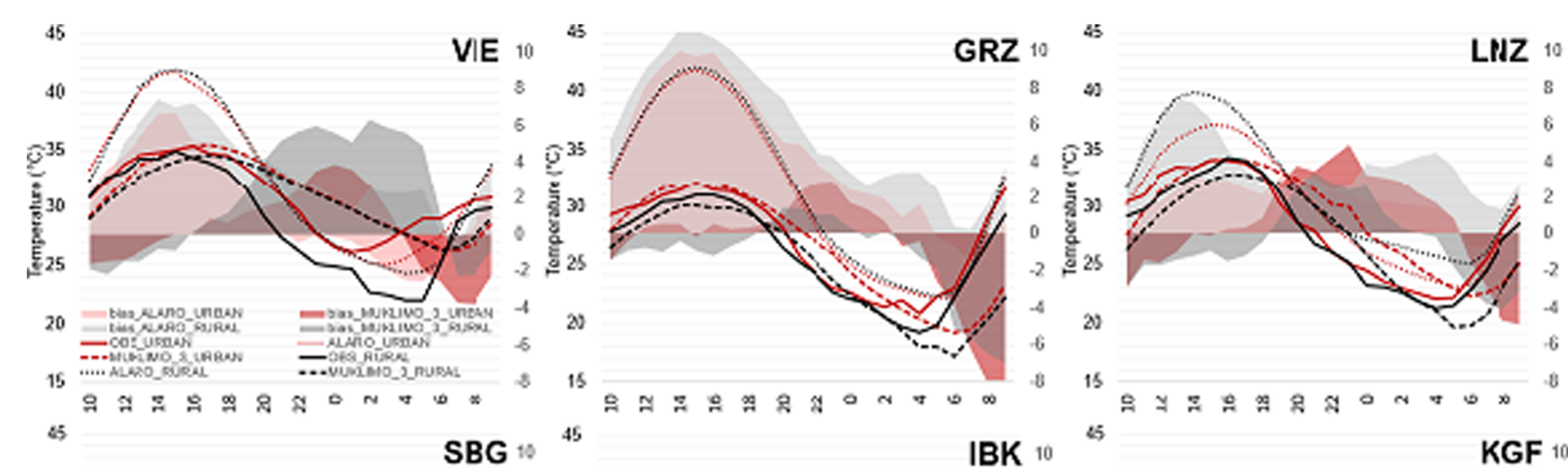

$$
45
$$
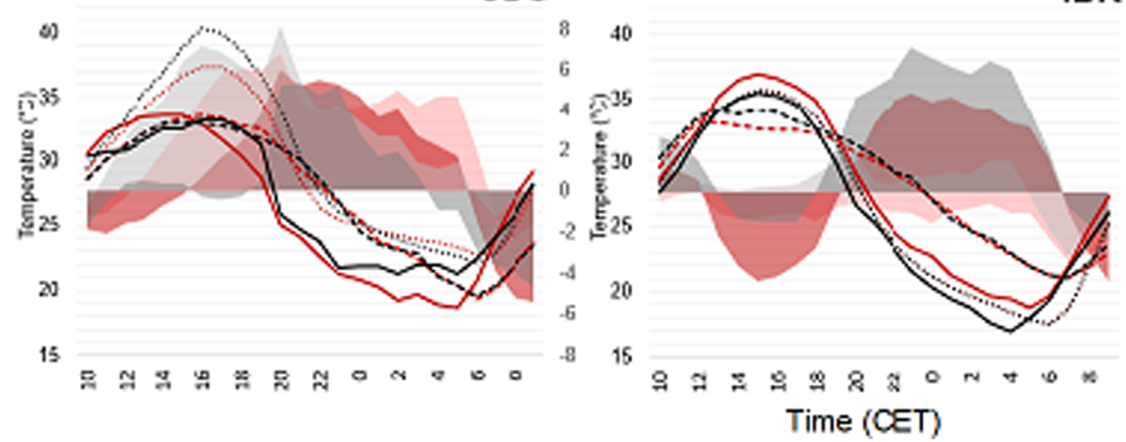

IBK 10
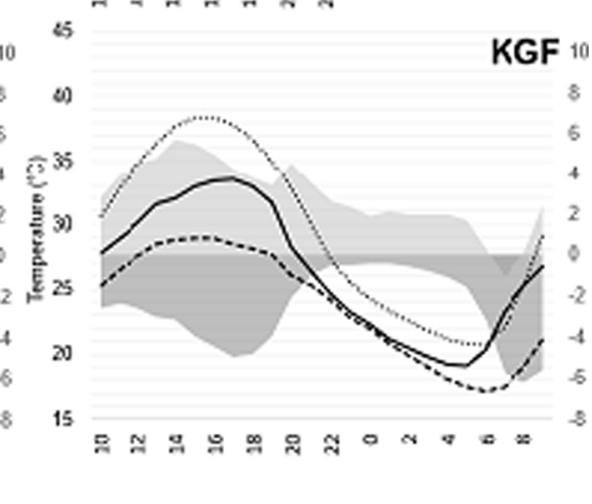

Fig. 12 Diurnal variation of air temperature at 2-m height and model bias in the analysed cities (secondary axis) for Vienna, Graz, Linz, Salzburg, Innsbruck, and Klagenfurt on 26 June 2019, provided by ALARO,

MUKLIMO_3, and the observations at the measurement stations in the rural and urban areas 

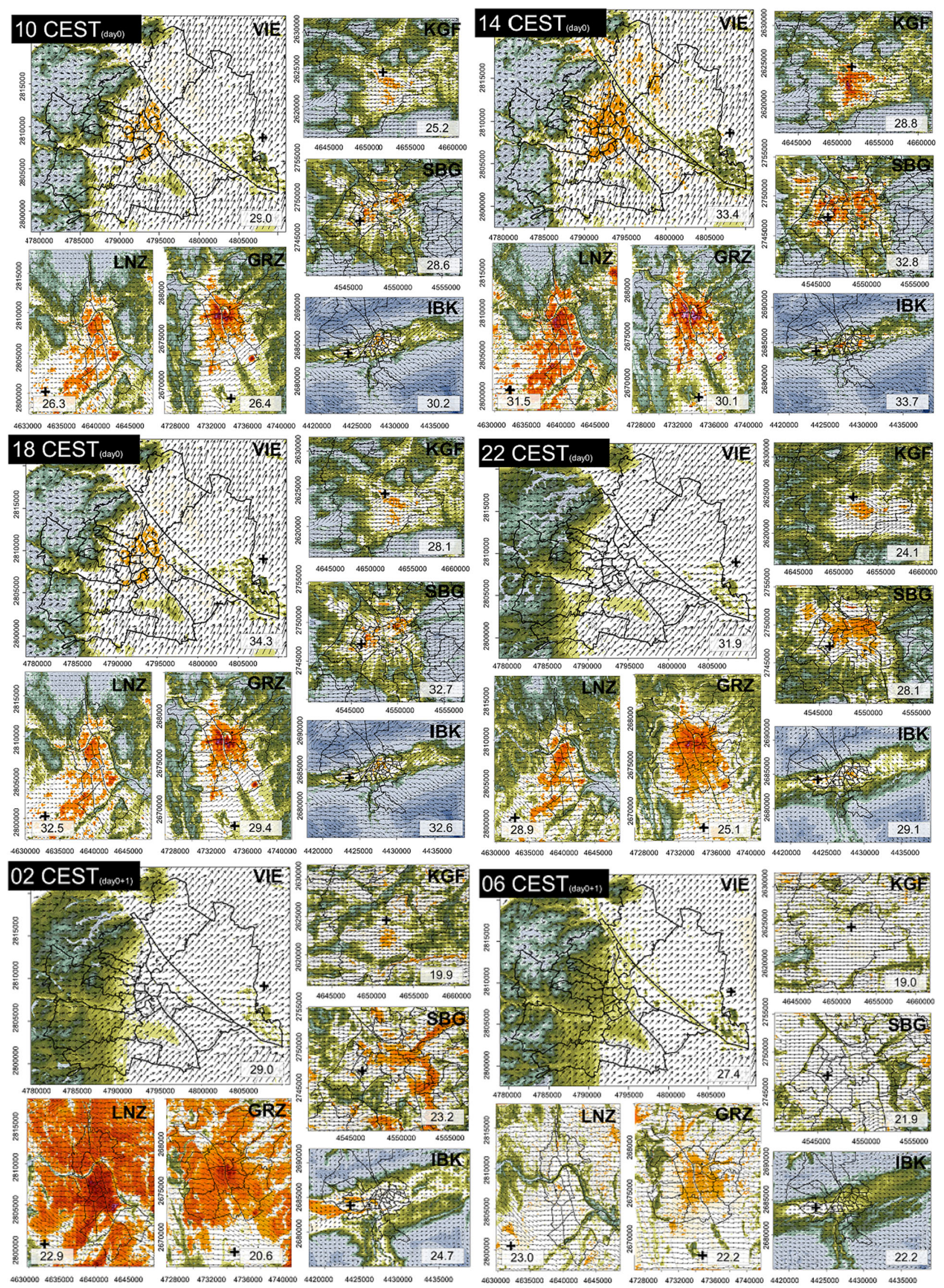
4 Fig. 13 Diurnal variation of spatial air temperature differences at 2-m height related to the reference station of the cities with the current wind field at 10-m height on 26 June 2019 modelled by MUKLIMO 3. Black crosses show the location of the reference station; values in the box bottom right indicate the modelled air temperature values $\left({ }^{\circ} \mathrm{C}\right)$ values of the reference station at the given time

and the city administration of Vienna, and it was evaluated during the summer period 1 April to 31 October 2019. Air temperature, relative humidity, and wind characteristics were analysed being relevant parameters for calculations of human thermal comfort indices, considered in the heat warning system of Austria.

Model evaluation confirmed that the MUKLIMO_3 microscale model had the capacity to simulate the main thermal spatiotemporal patterns in selected urban areas during the analysed period. However, a strong UCM dependence on the input data from the NWP mesoscale model was found. If the analysis fields initiated by ALARO were not representative for the given day, larger UCM-independent errors occurred. Since MUKLIMO_3 does not receive any information on changes in mesoscale conditions during the simulation period and does not include dynamical cloud processes, the initial data play a key role for the diurnal variability of incoming solar radiation. As diurnal ranges of temperature and relative humidity increase with decreasing cloud cover, while the diurnal variability is generally much lower if cloud cover increases, the model results highly dependent if the model was initialized with a negative or positive cloud cover bias. Excluding simulations from the analysis, where the parameter cloud cover was affected by an error of at least $50 \%$, could improve air temperature results of about $10 \%$. However, it should be noted that minor initiating biases do not automatically ensure better results due to changing atmospheric conditions over the simulation time. Apart from initial atmospheric conditions, e.g. soil parameters play also a crucial role in MUKLIMO_3 simulations. As soil temperature and moisture were not available as NWP model output, these parameters were provided by the reference stations of the cities. This information is, although, not quantified in the measurements and relies on a different classification scheme, leading to uncertainties in the simulations.

Lacking dynamical cloud processes contribute to difficulties in predicting the variability of humidity levels. The relative humidity predictions of MUKLIMO_3 appears to be much less plausible and show large variety of model prediction skills. Both models show similarly strong overestimations of low humidity conditions, and high humidity levels are generally underestimated in the UCM, especially if it is combined with high air temperatures. Because of the temperature dependence of relative humidity, statements regarding the $2 \mathrm{D}$ distribution of this parameter does not necessarily mean there is less water vapour content in urban air (Hage 1975). Relative humidity, as the only humidity quantity provided by the MUKLIMO_3 model, enables a direct comparison with the measurements of the observational stations. Calculated absolute humidity (total mass of water vapour in a given air mass without taking air temperature into consideration) results showed in mean differences of $\pm 2 \mathrm{~g} / \mathrm{m}^{3}$ in humidity content, where differences were correlating with variation of land cover and elevation (see Fig. 15 in Appendix). Despite the low roughness lengths defined in MUKLIMO_3_corresponding to the roughness length of the non-built-up area within the grid cell $(0.2 \mathrm{~m})$, while the roughness length of the buildings and trees are explicitly calculated based on the mean building and tree heights for each land use class-wind speed at 10-m height is underestimated by about $0.5-3 \mathrm{~m} / \mathrm{s}$ in mean (up to $4.5 \mathrm{~m} / \mathrm{s}$ in forested areas), with somewhat larger biases during daytime.

MUKLIMO_3 validation results showed a large benefit in prediction of maximum air temperatures in urban areas. Even though MUKLIMO_3 simulations produce relatively low biases for air temperature in the first 4-5 h of simulation (from 0.75 to $2.0^{\circ} \mathrm{C}$ ), during the nocturnal cooling, MUKLIMO_3 is generally less accurate, and a systematic large bias persists in the nighttime air temperature modelling (in average up to $4.5^{\circ} \mathrm{C}$ ). ALARO performed differently and had its largest biases (in average up to $4.0^{\circ} \mathrm{C}$ ) during daytime, when maximum temperature is normally reached. Although the MUKLIMO_3 model results have better standard deviation scores, they show about $4 \%$ lower correlation ratio $(0.90)$ and slightly larger (2\%) RMSE values with a range from $2.7{ }^{\circ} \mathrm{C}$ (Klagenfurt) up to $3.4{ }^{\circ} \mathrm{C}$ (Vienna) compared to ALARO. Based on the underrepresentation of complex terrain in the ALARO model, the weakest performance was assessed for Innsbruck with the largest RMSE values $\left(4.2^{\circ} \mathrm{C}\right)$ in ALARO, while MUKLIMO 3 had an RMSE of $3.2^{\circ} \mathrm{C}$.

The analysis shows a strong link between the intra-urban variability of air temperature, building and impervious characteristics, as well as green surface fractions (independent from the size of the cities). In Vienna and Innsbruck, an underestimation of UHI intensity over investigated summer period was found, while in Linz and Graz MUKLIMO_3 simulates larger urban-rural differences than observed. Apart from Salzburg, the largest UHI intensities were measured during night. However, the minor UHI intensity in Salzburg might be explained by the rural characteristics of the measurement stations.

Due to its size and largest population, it is expected that Vienna has the strongest UHI intensity, which was confirmed in this study, and increased negative impact of urban climate on its inhabitants. Observations indicate the largest UHI intensities (up to $7{ }^{\circ} \mathrm{C}$ ) as well as the largest variability for the capital city of Vienna. Compared to other cities, in Vienna, the third quantile and the median is of about 1.7 times higher. Nevertheless, high intensity 
and strong variations in UHI intensity were found in other cities as well, regardless of their comparatively smaller size and topographical setting in the mountains (e.g. Innsbruck and Graz).

It should be also noted that for the model evaluation procedure, in most cities, only a limited number of measurement stations were available. Traditional measuring networks are rarely suitable for city-specific or intraurban analysis being too coarse to record the variability of microscale climate. Ongoing analysis in this field shows that, even in cities with a relatively high amount of meteorological stations, the heat load pattern is not necessarily monitored properly enough resulting in large uncertainties in information for urban areas. Using lowcost measurements from alternative sources to capture local variations of urban heat load has generated much interest in the research community (Muller et al. 2015; Meier et al. 2017; Droste et al. 2017). Due to different quality control techniques, crowd-sourced data can bridge the gap in term of providing high-resolution and real-time air temperature measurements in densely populated areas that are of added value for microscale modelling and validation and may establish the basis for machine learning algorithms. The analysis of Feichtinger et al. (2020), where the authors provided first results of qualitycontrolled NETATMO data for Vienna, showed promising results in order to include these crowd-sourced data in the model validation process of MUKLIMO_3 simulations. In addition, the newly evolving research field of climate informatics, machine learning, can help further quantify the influence of surface characteristics on spatial variability in UHI.

In the last decade, the need for land cover and land use datasets suited for environmental studies increased extremely. Due to joint initiatives and efforts from different international cooperations aiming knowledge and information transfer based on scientific research, as well as enhancing benefit from international cooperations, different mapping techniques were developed. Hence, urban modelling approaches can apply land use and land cover information from several sources, and as the derived information is commonly used in decision-making, it is relevant to evaluate their impact and influence on, e.g. air temperature patterns, and to determine uncertainties arising from representations of land use information in different urban climate model applications. Conducted MUKLIMO 3 analyses for Vienna (Bokwa et al. 2019 using the $\overline{L C Z}$ scheme and Zuvela et al. 2014 using the classification of the city administration) showed comparable model biases. A detailed comparison of different land use schemes is currently analysed for selected Austrian cities in the ongoing research project called LUCRETIA
("The role of Land Use Changes on the development of intra-urban heat islands") funded by the Austrian Climate Research Programme (KR18AC0K14598).

The model simulations presented in this research were conducted on the ZAMG high-performance computing system using HPE Apollo 8600 environment. The MUKLIMO 3 thermodynamic model, available as a serial, single Fortran code, was compiled using the Intel Fortran Compiler with optimization options. The model runs were found quite time-intensive by nature requiring a simulation time from $2.5 \mathrm{~h}$ up to $5 \mathrm{~h}$ depending on domain complexity and atmospheric conditions (especially wind speed) and in more extreme situations up to $160 \mathrm{~h}$ (e.g. a windy day in Innsbruck), making it less practical for day-to-day utilization. Simulation time could be improved without significant information loss by increasing the horizontal resolution to $200 \mathrm{~m}$ in cities with more complex terrain; however, this intention might be relevant only from computational, but not from thematic perspective. In summer 2019, DWD released a new modernized and modular structured official version of the microscale model MUKLIMO_3 in F90 programming language, which enables further developments of code parallelization, as well as considering 2D input data of LU characteristics being less dependent from LU classifications. The newly introduced MUKLIMO_3 code could significantly decrease the required simulation time making the process more suitable for daily applications.

The knowledge gained within this study can be a contribution to the urban climate research community. However, methods and results should be further tested in other cities with similar and different climates (e.g. Bokwa et al. 2019). Since results can vary due to specific atmospheric situations, as well as geographic and urban characteristics, the successful application might depend on the availability of land surface data, the measurement stations in the urban area, as well as the computational resources to perform the simulations. The results of this study can be not only relevant for urban climate research but also considered as a basis for NWP model intercomparison, as well as for improving understanding of the sensitivity of different NWP urban parameterizations, especially in case of, e.g. high-pressure weather situations, when ALARO often forecasted unrealistic maximum air temperatures for urban surroundings. Research findings can help to identify hot zones in cities under different weather conditions, provide information for urban planning and climate adaptation activities, improve the preparedness for heat events, and contribute to improve existing risk management strategies and practices for natural hazards related to excessive heat. 


\section{Appendix}

Table 3 The Urban Atlas nomenclature and parameters for land use properties range in MUKLIMO_3 model for the analysed cities: fraction of built area $\left(\gamma_{\mathrm{b}}\right)$, mean building height $\left(h_{b}\right)$, fraction of pavement $(v)$ where the correct model specific value for water is -1 , fraction of tree cover $\left(\sigma_{t}\right)$, and fraction of low vegetation $\left(\sigma_{\mathrm{c}}\right)$. Fractions $\gamma_{\mathrm{b}}$ and $\sigma_{\mathrm{t}}$ are relative to the total grid cell area. $v$ is relative to the area without buildings and trees and $\sigma_{\mathrm{c}}$ is relative to the remaining surface. Land use classes marked cursive can be found only in some city domains; therefore, the indicated values are based on statistics only of cities where they occur

\begin{tabular}{|c|c|c|c|c|c|c|}
\hline Code & Urban Atlas nomenclature & $\gamma_{b}(\%)$ & $h_{b}(\mathrm{~m})$ & $\mathrm{v}(\%)$ & $\sigma_{t}(\%)$ & $\sigma_{c}(\%)$ \\
\hline 11100 & Continuous urban fabric & $0.33-0.45$ & $12.00-20.00$ & $0.55-0.75$ & 0.00 & $0.70-0.81$ \\
\hline 11210 & Discontinuous dense urban fabric & $0.20-0.30$ & $8.00-15.00$ & $0.29-0.49$ & 0.00 & $0.70-0.78$ \\
\hline 11220 & Discontinuous medium-density urban fabric & $0.15-0.22$ & $6.00-8.00$ & $0.20-0.35$ & 0.00 & $0.70-0.89$ \\
\hline 11230 & Discontinuous low-density urban fabric & $0.14-0.16$ & $5.00-9.00$ & $0.10-0.26$ & 0.00 & $0.78-0.87$ \\
\hline 11240 & Discontinuous very low-density urban fabric & $0.09-0.14$ & $5.00-9.00$ & $0.07-0.22$ & 0.00 & $0.80-0.89$ \\
\hline 11300 & Isolated structures & $0.05-0.14$ & $5.50-12.00$ & $0.05-0.16$ & 0.00 & $0.31-0.91$ \\
\hline 12100 & Industrial, commercial, public, military, and private units & $0.11-0.31$ & $7.00-10.00$ & $0.33-0.60$ & 0.00 & $0.40-0.86$ \\
\hline 12210 & Fast transit roads and associated land & 0.00 & 0.00 & $0.35-0.65$ & $0.05-0.28$ & $0.27-0.65$ \\
\hline 12220 & Other roads and associated land & 0.00 & 0.00 & $0.42-0.66$ & $0.07-0.17$ & $0.39-0.86$ \\
\hline 12230 & Railways and associated land & 0.00 & 0.00 & $0.44-0.82$ & $0.04-0.10$ & $0.39-0.71$ \\
\hline 12300 & Port areas & $0.00-0.30$ & $5.00-10.20$ & $0.00-0.71$ & $0.00-0.02$ & $0.11-0.64$ \\
\hline 12400 & Airports & $0.04-0.20$ & $4.00-9.00$ & $0.11-0.78$ & $0.00-0.02$ & $0.49-0.98$ \\
\hline 13100 & Mineral extraction and dump sites & $0.00-0.05$ & $0.00-13.00$ & $0.07-0.61$ & $0.00-0.08$ & $0.12-0.56$ \\
\hline 13300 & Construction sites & $0.03-0.15$ & $6.00-10.30$ & $0.14-0.26$ & $0.00-0.06$ & $0.07-0.93$ \\
\hline 13400 & Land without current use & 0.00 & 0.00 & $0.20-0.35$ & $0.06-0.15$ & $0.72-0.80$ \\
\hline 14100 & Green urban areas & 0.00 & 0.00 & $0.11-0.30$ & $0.18-0.61$ & $0.84-0.96$ \\
\hline 14200 & Sports and leisure facilities & 0.00 & 0.00 & $0.17-0.32$ & $0.07-0.23$ & $0.68-0.78$ \\
\hline 21000 & Arable land (annual crops) & 0.00 & 0.00 & $0.02-0.09$ & $0.03-0.18$ & $0.80-0.90$ \\
\hline 22000 & Permanent crops & 0.00 & 0.00 & $0.00-0.13$ & $0.00-0.28$ & $0.88-0.94$ \\
\hline 23000 & Pastures & 0.00 & 0.00 & $0.00-0.03$ & $0.04-0.23$ & $0.75-0.95$ \\
\hline 24000 & Complex and mixed cultivation patterns & 0.00 & 0.00 & $0.00-0.05$ & 0.11 & 0.90 \\
\hline 25000 & Orchards at the fringe of urban classes & 0.00 & 0.00 & $0.00-0.05$ & 0.11 & 0.90 \\
\hline 31000 & Forests & 0.00 & 0.00 & $0.00-0.02$ & $0.60-0.83$ & $0.70-0.99$ \\
\hline 32000 & Herbaceous vegetation associations & 0.00 & 0.00 & $0.00-0.05$ & $0.39-0.47$ & $0.94-1.00$ \\
\hline 33000 & Open spaces with little or no vegetation & 0.00 & 0.00 & 0.00 & 0.00 & 0.00 \\
\hline 40000 & Wetlands & 0.00 & 0.00 & -1.00 & 0.00 & 0.00 \\
\hline 50000 & Water & 0.00 & 0.00 & -1.00 & 0.00 & 0.00 \\
\hline
\end{tabular}


Fig. 14 Modelled air temperatures by Urban Atlas land use categories over at 14 CEST and 02 CEST on 26 June 2019 simulated by MUKLIMO_3 using violin plot

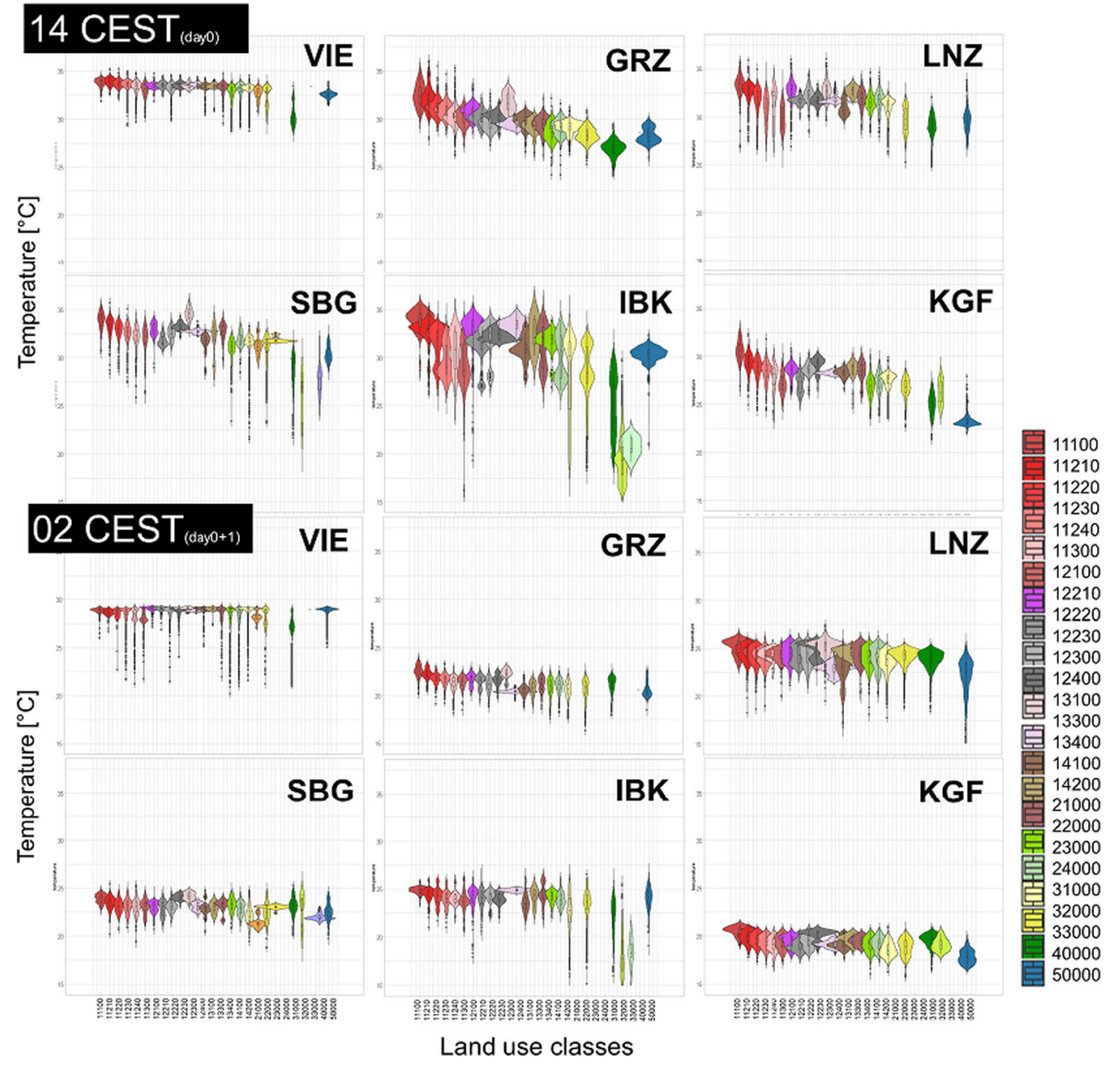


Fig. 15 Difference of absolute humidity daily means compared to the reference station of each city over the whole period (1 April-31 October 2019) simulated by the MUKLIMO_3 model
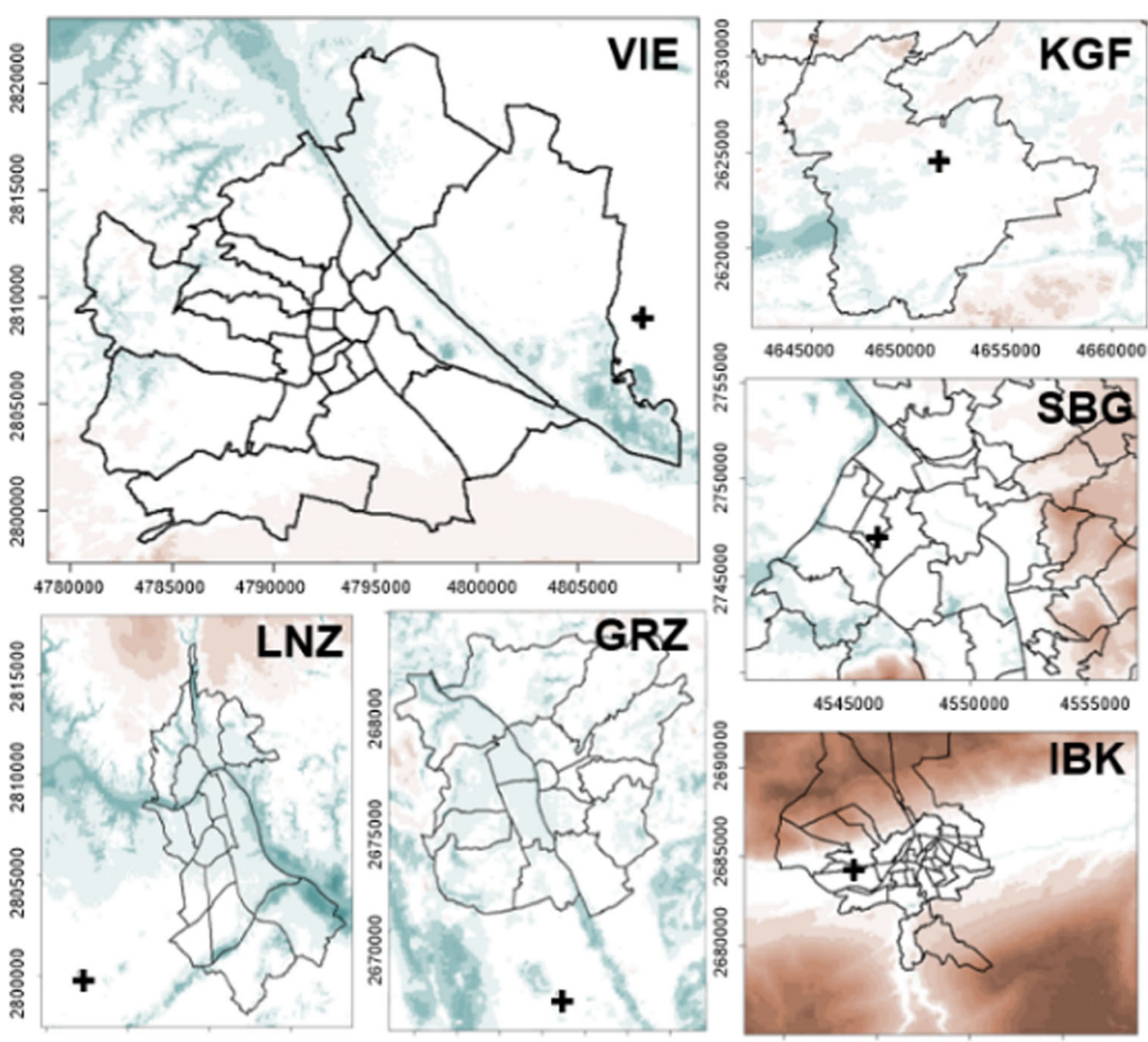

$4630000 \quad 4635000 \quad 4640000 \quad 4645000$

$4728000 \quad 4732000 \quad 4736000 \quad 4740000$

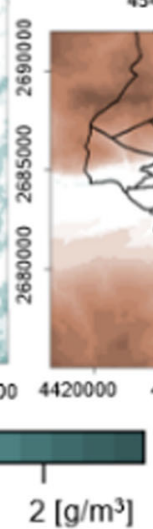

IBK
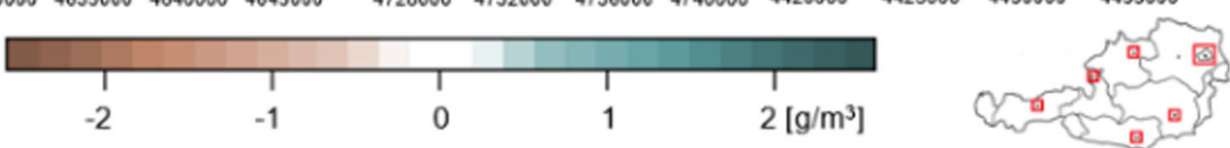
Acknowledgements The authors thank the German Meteorological Service (DWD) for providing the MUKLIMO_3 model for research purposes and for their support, as well as the city administrations of Vienna, Graz, Linz, Salzburg, Innsbruck, and Klagenfurt for the local datasets on urban characteristics considered in the model simulations.

Author contribution All authors contributed to the study conception and design. Data collection was done by Sandro Oswald, Astrid Kainz, Maja Zuvela-Aloise, and Brigitta Hollosi. The model setup, simulations, and evaluation were performed by Brigitta Hollosi. The first draft of the manuscript was written by Brigitta Hollosi, and all authors commented on previous versions of the manuscript. All authors read and approved the final manuscript

Funding This study was funded by the Austrian Federal Ministry of Education, Science and Research (BMBWF) as part of the ZAMG internal research project MoDuLus.

\section{Declarations}

Conflict of interest The authors declare no competing interests.

Open Access This article is licensed under a Creative Commons Attribution 4.0 International License, which permits use, sharing, adaptation, distribution and reproduction in any medium or format, as long as you give appropriate credit to the original author(s) and the source, provide a link to the Creative Commons licence, and indicate if changes were made. The images or other third party material in this article are included in the article's Creative Commons licence, unless indicated otherwise in a credit line to the material. If material is not included in the article's Creative Commons licence and your intended use is not permitted by statutory regulation or exceeds the permitted use, you will need to obtain permission directly from the copyright holder. To view a copy of this licence, visit http://creativecommons.org/licenses/by/4.0/.

\section{References}

AGES - Hitze-Mortalitätsmonitoring (2020) https://www.ages.at/themen/ umwelt/informationen-zu-hitze/hitze-mortalitaetsmonitoring/ (accessed: 26 February 2020)

Barriopedro D, Fischer EM, Luterbacher J, Trigo RM, García-Herrera R (2011) The hot summer of 2010: redrawing the temperature record map of Europe. Science 332:220-224

Bénard P, Vivoda J, Masek J, Smolikova P, Yessad K, Smith C, Brozkova R, Geleyn JF (2010) Dynamical kernel of the Aladin$\mathrm{NH}$ spectral limited-area model: formulation and sensitivity experiments. Quart J Roy Meteor Soc 136A:155-169. https://doi.org/10. $1002 /$ qj.522

Bokwa A, Dobrovolny P, Gal T, Geletic J, Gulyas A, Hajto MJ, Hollosi B, Kielar R, Lehnert M, Skarbit N, Stastny P, Svec M, Unger J, Vysoudil M, Walawender JP, Zuvela-Aloise M (2018) Urban climate in central European cities and global climate change. Acta Climatologica et Chronologica, Universitatis Szegediensis, Tomus 51-52:7-35

Bokwa A, Geletic J, Lehnert M, Zuvela-Aloise M, Hollosi B, Gal T, Skarbit N, Dobrovolny P, Hajto MJ, Kielar R, Walawender JP, Stastny P, Holec J, Ostapowic K, Burianova J, Garaj M (2019) Heat load assessment in central European cities using an urban climate model and observational monitoring data. Energy and Buildings 201:53-69
Bornstein RD, Johnson DS (1976) Urban rural wind velocity differences. Atmos Environ 11:597-604

Casanueva A, Burgstall A, Kotlarski S, Messeri A, Morabito M, Flouris AD, Nybo L, Spirig C, Schwierz C (2019) Overview of existing heat-health warning systems in Europe. Int J Environ Res Public Health 16:2657

Chen F, Kusaka H, Bornstein R, Ching J, Grimmond CSB, GrossmannClarke S, Loridan T, Manning KW, Martilli A, Miao S, Sailor D, Salamanca FP, Taha H, Tewari M, Wang X, Wsyszogrodzki AA, Zhang C (2011) The integrated WRF/urban modelling system: development, evaluation, and applications to urban environmental problems. Int J Climatol 31:273-288. https://doi.org/10.1002/joc. 2158

Cotton WR, Pielke RA (1995) Human impacts on weather and climate. Cambridge University Press, New York, p 288

De Ridder K, Lauwaet D, Maiheu B (2015) UrbClim - a fast urban boundary layer climate model. Urban Climatology 12:21-48. https://doi.org/10.1016/j.uclim.2015.01.001

Dixon PG, Mote TL (2003) Patterns and causes of Atlanta's urban heat island-initiated precipitation. J Appl Meteorol 42(9):1273-1284

Droste AM, Pape JJ, Overeem A, Leijnse H, Steeneveld GJ, Van Delden AJ, Uijlenhoet R (2017) Crowdsourcing urban air temperatures through smartphone battery temperatures in São Paulo, Brazil. J Atmos Ocean Technol 34(9):1853-1866. https://doi.org/10.1175/ JTECH-D-16-0150.1

EEA (2010) The GMES urban atlas. European Environment Agency, Copenhagen. http://www.eea.europa.eu/data-and-maps/data/urbanatlas

Fallmann J, Emeis S, Suppan P (2014) Mitigation of urban heat stress - a modelling case study for the area of Stuttgart. Die Erde, Journal of the Geographical Society of Berlin 144:202-216

Feichtinger M, de Wit R, Goldenits G, Kolejka T, Hollosi B, ZuvelaAloise M, Feigl J (2020) Case-study of neighborhood-scale summertime urban air temperature for the city of Vienna using crowdsourced data. Urban Climate 32:32. https://oi.org/10.1016/j.uclim. 2020.100597

Figuerola PI, Mazzeo NA (1998) Urban-rural temperature differences in Buenos Aires. Int J Climatol 18:1709-1723

Fischer EM, Schär C (2010) Consistent geographical patterns of changes in high-impact European heatwaves. Nat Geosci 3:398-403. https:// doi.org/10.1038/NGEO866

Früh B, Becker P, Deutschländer T (2011) Estimation of climate-change impacts on the urban heat load using an urban climate model and regional climate projections. J Appl Meteorol Climatol 50:167-184. https://doi.org/10.1175/2010JAMC2377.1

Garcia-Diez M, Lauwaet D, Hooyberghs H, Ballester J, De Ridder K, Rodó X (2016) Advantages of using a fast urban boundary layer model as compared to a full mesoscale model to simulate the urban heat island of Barcelona. Geoscientific Model Developments 9: 4439-4450. https://doi.org/10.5194/gmd-9-4439-2016

GCOS (2017) Global climate observing system Austrian inventory report, Bundesministerium für Wissenschaft, Forschung und Wirtschaft (BMWFW), Zentralanstalt für Meteorologie und Geodynamik (ZAMG). Editors: Silke Adler and Hermine Fürst, ZAMG, pp 113. available: https://www.zamg.ac.at/cms/de/ dokumente/topmenu/gcos/gcos-report-2017

Göndöcs J, Breuer H, Pongracz R, Bartholy J (2017) Urban heat island mesoscale modelling study for the Budapest agglomeration area using the WRF model. Urban Clim 21:66-86. https://doi.org/10. 1016/j.uclim.2017.05.005

Grimmond CS, Blackett M, Best MJ, Barlow J, Baik J, Belcher SE, Bohnenstengel SI, Calmet I, Chen F, Dandou A, Fortuniak K, Gouvea ML, Hamdi ML, Hendry ML, Kawai T, Kawamoto Y, Kondo H, Krayenhoff ES, Lee S, Loridan T, Martilli A, Masson V, Miao S, Oleson K, Pigeon G, Porson A, Ryu Y, Salamanca F, Shashua-Bar L, Steeneveld G, Tombrou M, Voogt J, Young D, 
Zhang N (2010) The international urban energy balance models comparison project: first results from phase 1. J Appl Meteorol Climatol 49:1268-1292. https://doi.org/10.1175/2010JAMC2354.1

Grimmond CSB, Blackett M, Best MJ, Baik JJ, Belcher SE, Beringer J, Dandou A (2011) Initial results from phase 2 of the international urban energy balance model comparison. Int J Climatol 31(2):244 272

Gross G (1989) Numerical simulations of the nocturnal flow systems in the Freiburg area for different topographies. Beiträge zur Phys Atmos 62:57-72

Hage K (1975) Urban-rural humidity differences. J Appl Meteorol 14(7): 1277-1283

Hamdi R, Schayes G (2008) Sensitivity study of the urban heat island intensity to urban characteristics. Int J Climatol 28:973-982. https:// doi.org/10.1016/j.uclim.2020.100582

IPCC (2013) Climate change 2013: the physical science basis. In: Stocker TF, Qin D, Plattner GK, Tignor M, Allen SK, Boschung J, Nauels A, Xia Y, Bex V, Midgley PM (eds) Contributionof working group I to the fifth assessment report of the intergovernmental panel on climate change. Cambridge University Press, Cambridge, United Kingdom and New York, NY, USA, p 1535. https://doi.org/10. 1017/CBO9781107415324

Kainz A, Zuvela-Aloise M, Goler R, de Wit R, Hahn C (2019) Demonstrating the effects of climate adaptation measures for the Austrian city of Linz as part of CLARITY's climate services. Zenodo. https://doi.org/10.5281/zenodo.3532656

Kann A, Wittmann C, Bica B, Wastl C (2015) On the impact of NWP model background on very high resolution analyses in complex terrain. Weather Forecast 30:1077-1089. https://doi.org/10.1175/ WAF-D-15-0001.1

Kleerekoper L, van Esch M, Salcedo TB (2012) How to make a city climate-proof, addressing the urban heat island effect. Resour Conserv Recycl 64:30-38

Kovats RS, Jendritzky G (2006) Heat-waves and human health. In: Menne B, Ebi KL (eds) Climate change and adaptation strategies for human health. Springer, Dortrecht, p 449

Kusaka H, Kondo H, Kikegawa Y, Kimura F (2001) A simple singlelayer urban canopy model for atmospheric models: comparison with multi-layer and slab models. Boundary Layer Meteorol 101:329358

Landsberg HE (1981) The urban climate, international geophysical. Series, 28. Academic Press, New York, p 275

Lee DO (1991) Urban-rural humidity differences in London. Int J Climatol 11(5):577-582

Lowe D, Ebi KL, Forsberg B (2011) Heatwave early warning systems and adaptation advice to reduce human health consequences of heatwaves. Int J Environ Res Public Health 8:4623-4648. https:// doi.org/10.3390/ijerph8124623

Martilli A, Clappier A, Rotach MW (2002) An urban surface exchange parameterisation for mesoscale models. Boundary Layer Meteorology 104:261-304

Masson V (2000) A physically-based scheme for the urban energy budget in atmospheric models. Boundary Layer Meteorology 94:357-397

Meier F, Fenner D, Grassmann T, Otto M, Scherer D (2017) Crowdsourcing air temperature from citizen weather stations for urban climate research. Urban Clim 10:170-191

Molnár G, Gyöngyösi AZ, Gál T (2019) Integration of an LCZ-based classification into WRF to assess the intra-urban temperature pattern under a heatwave period in Szeged, Hungary. Theor Appl Climatol 138:1139-1158. https://doi.org/10.1007/s00704-019-02881-1

Muller CL, Chapman L, Johnston S, Kidd C, Illingworth S, Foody G, Overeem A, Leigh RR (2015) Crowdsourcing for climate and atmospheric sciences: current status and future potential. Int J Climatol 35(11):3185-3203
Nguyen JL, Schwartz J, Dockery DW (2013) The relationship between indoor and outdoor temperature, apparent temperature, relative humidity, and absolute humidity. Indoor Air 24(1):103-112

Oke TR (1973) City size and the urban heat island. Atmos Environ 7: 769-779

Oke TR (1982) The energetic basis of the urban Heat Island. Q J R Meteorol Soc 108:1-24

Oke TR (1995) The heat island of the urban boundary layer: characteristics, causes and effects. In: Cermak JE, Davenport AG, Plate EJ, Viegas DX (eds) Wind climate in cities. NATO ASI series (series E: applied sciences), vol 277. Springer

Österreichischer Städtebund (2017) Österreischs Städte in Zahlen. ISBNNr. 978-3-9502038-3-7, Wien, 2018

Oswald S, Hollosi B, Zuvela-Aloise M, See L, Guggenberger S, Hafner W, Prokop G, Storch A, Schieder W (2020) Using urban climate modelling and improved land use classifications to support climate change adaptation in urban environments: a case study for the city of Klagenfurt. Austria, Urban Climate 31:100582 ISSN 2212-0955

Pekarova P, Halmova D, Miklanek P, Onderka M, Pekar J, Skoda P (2008) Is the water temperature of the Danube River at Bratislava, Slovakia, rising? J Hydrometeorol 9:1115-1122. https://oi.org/10. 1175/2008JHM948.1

Robine JM, Cheung SL, Le Roy S, Van Oyen H, Griffiths C, Michel JP, Herrmann FR (2008) Death toll exceeded 70,000 in Europe during the summer of 2003. Comptes Rendus Biologies 331(2):171-178

Ronda R, Heusinkveld B, Steeneveld GJ, Attema JJ, Holtslag B (2017) Urban station data for the city of Amsterdam for the summer of 2015. PANGAEA. https://doi.org/10.1594/PANGAEA.877502

Rooney C, McMichael AJ, Kovats RS, Coleman MP (1998) Excess mortality in England and Wales, and in greater London, during the 1995 heat wave. J Epidemiol Community Health 52(8):482-486

Salamanca F, Krpo A, Martilli A, Clappier A (2010) A new building energy model coupled with an urban canopy parameterization for urban climate simulations-part I. Formulation, verification, and sensitivity analysis of the model, Theoretical and Applied Climatology 99:331-344

Salamanca F, Martilli A, Tewari M, Chen F (2011) A study of the urban boundary layer using different urban parameterizations and highresolution urban canopy parameters with WRF. J Appl Meteorol Climatol 50:1107-1128

Santamouris M, Gaitani N, Spanou A, Saliari M, Giannopoulou K, Vasilakopoulou K, Kardomateas T (2012) Using cool paving materials to improve microclimate of urban areas - design realization and results of the flisvos project. Build Environ 53:128-136

Schär C, Jendritzky G (2004) Climate change: hot news from summer 2003. Nature 432:559-560

Shepherd JM, Pierce H, Negri AJ (2002) Rainfall modifi- cation by major urban areas: observations from spaceborne rain radar on the TRMM satellite. J Appl Meteorol 41:689-701

Siebert J, Sievers U, Zdunkowski W (1992) A one-dimensional simulation of the interaction between land surface processes and the atmosphere. Boundary-Layer Meteorology 59:1-34

Sievers U (1990) Dreidimensionale Simulationen in Stadtgebieten. Umweltmeteorologie, Schriftenreihe Band 15: Sitzung des Hauptausschusses II am 7. und 8. Juni in Lahnstein. Kommission Reinhaltung der Luft im VDI und DIN, Düsseldorf, pp. 92-105

Sievers U (1995) Verallgemeinerung der Stromfunktionsmethode auf drei Dimensionen (generalization of the streamfunctionvorticity method to three dimension). Meteorol Z 3:3-15

Sievers U (2016) Das kleinskalige Strömungsmodell MUKLIMO_3. Teil 2: Thermodynamische Erweiterungen. - Offenbach am Main: Selbstverlag des Deutschen Wetterdienstes. (Berichte des Deutschen Wetterdienstes ; 248)

Sievers U, Zdunkowski W (1986) A microscale urban climate model. Physical Atmosphere 59:13-40 
Sievers U, Forkel R, Zdunkowski W (1983) Transport equations for heat and moisture in the soil and their application to boundary layer problems. Beiträge Physik der Atmosphäre 56:58-83

Skamarock WC, Klemp JB (2008) A time-split nonhydrostatic atmospheric model for weather research and forecasting applications. J Comput Phys 227:3465-3485. https://doi.org/10.1016/j.jcp.2007. 01.037

Statistics Austria (2019) Bevölkerungsprognose 2019 http://www.statistik. at/web_de/statistiken/menschen_und_gesellschaft/bevoelkerung/ demographische_prognosen/bevoelkerungsprognosen/027317.html (accessed: 26 February 2020)

Stewart ID, Oke TR (2012) Local Climate Zones for urban temperature studies. Bull Am Meteorol Soc 93:1879-1900

Taylor KE (2001) Summarizing multiple aspects of model performance in a single diagram. J Geophys Res 106:7183-7192. https://doi.org/ 10.1029/2000JD900719

Theeuwes NE, Solcerova A, Steeneveld GJ (2013) Modeling the influence of open water surfaces on the summertime temperature and thermal comfort in the city. Journal of Geophysical Research: Atmospheres 118:8881-8896

Vuckovic M, Hammerberg K, Mahdavi A (2020) Urban weather modeling applications: a Vienna case study. Building Simulations 13:99111. https://doi.org/10.1007/s12273-019-0564-y

Wang Y, Haiden T, Kann A (2006) The operational limited area Modelling system at ZAMG: ALADIN-AUSTRIA,
Österreichische Beiträge zu Meteorologie und Geophysik. Vol. 37: 33

WMO, WHO (2015) Heatwaves and health: guidance on warning system development, McGregor, G.R., Bessemoulin, P., Ebi, K., and Menne, B. (eds.), WMO, Geneva, pp. 114 https://www.who.int/ globalchange/publications/WMO_WHO_Heat_Health_Guidance 2015.pdf?ua $=1$

Zhang DL, Shou YX, Dickerson RR, Chen F (2011) Impact of upstream urbanization on the urban heat island effects along the WashingtonBaltimore corridor. Journal of applied meteorology and climatology:2012-2029

Zuvela-Aloise M (2017) Enhancement of urban heat load through social inequalities on an example of a fictional city king's landing. Int J Biometeorol 61:527-539. https://doi.org/10.1007/s00484-016$1230-\mathrm{Z}$

Zuvela-Aloise M, Koch R, Neureiter A, Böhm R, Buchholz S (2014) Reconstructing urban climate of Vienna based on historical maps dating to the early instrumental period. Urban Clim 10:490-508

Zuvela-Aloise M, Koch R, Buchholz S, Früh B (2016) Modelling the potential of green and blue infrastructure to reduce urban heat load in the city of Vienna. Clim Chang 135:425-438. https://doi.org/10. 1007/s10584-016-1596-2

Publisher's note Springer Nature remains neutral with regard to jurisdictional claims in published maps and institutional affiliations. 